\title{
Broa, an Ethnic Maize Bread, as a Source of Phenolic Compounds
}

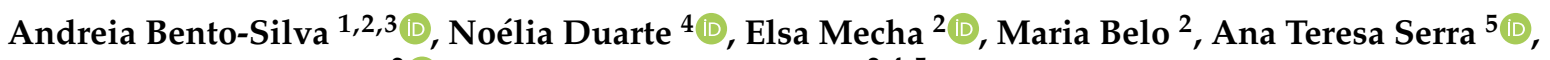 \\ Maria Carlota Vaz Patto ${ }^{2}$ and Maria Rosário Bronze ${ }^{2,4,5, *}$
}

1 FCT NOVA, Faculdade de Ciências e Tecnologia, Campus da Caparica, Universidade Nova de Lisboa, 2829-516 Caparica, Portugal; abentosilva@ff.ulisboa.pt

2 ITQB NOVA, Instituto de Tecnologia Química e Biológica António Xavier, Universidade Nova de Lisboa, Avenida da República, 2780-157 Oeiras, Portugal; emecha@itqb.unl.pt (E.M.); mariabelo87@gmail.com (M.B.); cpatto@itqb.unl.pt (M.C.V.P.)

3 FFULisboa, Faculdade de Farmácia da Universidade de Lisboa, Av. das Forças Armadas, 1649-019 Lisboa, Portugal

4 iMed.ULisboa, Instituto de Investigação do Medicamento, Faculdade de Farmácia, Universidade de Lisboa, Avenida Prof. Gama Pinto, 1649-003 Lisboa, Portugal; mduarte@ff.ulisboa.pt

5 iBET, Instituto de Biologia Experimental e Tecnológica, Avenida da República, Quinta-do-Marquês, Estação Agronómica Nacional, Apartado 12, 2780-157 Oeiras, Portugal; tserra@ibet.pt

* Correspondence: mbronze@ibet.pt

Citation: Bento-Silva, A.; Duarte, N.; Mecha, E.; Belo, M.; Serra, A.T.; Vaz Patto, M.C.; Bronze, M.R. Broa, an Ethnic Maize Bread, as a Source of Phenolic Compounds. Antioxidants 2021, 10, 672. https://doi.org/ 10.3390/antiox10050672

Academic Editors: Monica Rosa Loizzo and Rosa Tundis

Received: 27 March 2021

Accepted: 24 April 2021

Published: 26 April 2021

Publisher's Note: MDPI stays neutral with regard to jurisdictional claims in published maps and institutional affiliations.

Copyright: (c) 2021 by the authors. Licensee MDPI, Basel, Switzerland. This article is an open access article distributed under the terms and conditions of the Creative Commons Attribution (CC BY) license (https:// creativecommons.org/licenses/by/ $4.0 /)$.
Abstract: Maize is an important source of phenolic compounds, specially hydroxycinnamic acids, which are widely known for their antioxidant activity and associated health benefits. However, these effects depend on their bioaccessibility, which is influenced by the different techniques used for food processing. Several traditional products can be obtained from maize and, in Portugal, it is used for the production of an ethnic bread called broa. In order to evaluate the effect of processing on maize phenolic composition, one commercial hybrid and five open-pollinated maize flours and broas were studied. The total phenolic content and antioxidant activity were evaluated by the FolinCiocalteu and ORAC assays, respectively. The major phenolics, namely ferulic and $p$-coumaric acids (in their soluble-free, soluble-conjugated and insoluble forms), insoluble ferulic acid dimers and soluble hydroxycinnamic acid amides were quantitated. Results show that the total phenolic content, antioxidant activity and hydroxycinnamic acids resisted traditional processing conditions used in the production of broas. The content in soluble-free phenolics increased after processing, meaning that their bioaccessibility improved. Portuguese traditional broas, produced with open-pollinated maize varieties, can be considered an interesting dietary source of antioxidant compounds due to the higher content in hydroxycinnamic acids and derivatives.

Keywords: maize; broa; ferulic acid; p-coumaric acid; dehydrodiferulic acids; hydroxycinnamic acid amides

\section{Introduction}

Maize (Zea mays) is considered a staple cereal in many countries, where it is used to prepare different types of food products [1]. In Portugal, maize is the main ingredient (50-100\%) of an ethnic bread known as broa. Rye, wheat, (0-50\%) or a combination of the flours are also commonly added to the recipe [2]. Broas are traditionally prepared using open-pollinated maize varieties. However, Portuguese maize landraces are at risk of disappearing, due to the progressive adoption of more productive hybrid varieties, which originate broas less appreciated by consumers [2].

Epidemiological studies have demonstrated that the consumption of phenol-rich foods, as wholegrain cereals, in a regular diet is inversely associated with the risk of developing chronic diseases, such as oncologic and cardiovascular diseases, and metabolic 
syndrome [3]. Compared to other cereals, maize contains a high level of phenolic compounds, specially hydroxycinnamic acids, which can be found in their soluble or insoluble forms [4]. In particular, the ferulic acid (FA) content is at least ten-fold higher than in other cereal grains, which makes maize one of the most interesting sources of FA in the human diet [4]. Soluble phenolic compounds can be present in their free form or conjugated with smaller molecules, such as simple sugars and amines, as hydroxycinnamic acid amides [5-9]. Insoluble phenolic compounds are mostly ( $>94 \%)$ bound to arabinoxylans $[4,5,10]$, and include dehydrodiferulic, dehydrotriferulic and dehydrotetraferulic acids $[4,5]$ and their derivatives, such as the recently described insoluble hydroxycinnamic acid amides [11].

Evidence from human intervention trials on the protective effects of phenol-rich foods, such as wholegrains, has been inconsistent, mainly due to differences in the food composition and in the bioaccessibility and bioavailability of phenolic compounds [3]. Their bioaccessibility is influenced by the processing techniques involved in the preparation of food products $[4,12]$. Soluble compounds are usually available for absorption by a simple diffusion mechanism [4,13]. Conversely, insoluble compounds have a very low bioaccessibility $[4,13]$ and need to be liberated from the food matrix during small intestinal digestion or colonic fermentation, in order to be absorbed and become bioavailable [12] In a previous study, several phenolic compounds, mainly hydroxycinnamic acids and hydroxycinnamic acid amides, were identified in maize flours and broas [11].

Since the total content and bioaccessibility of phenolic compounds is influenced by the techniques used for food processing [3], it is mandatory to evaluate the phenolic composition of the final food product. The understanding of the influence of processing also allows the selection of processing conditions that are capable of preserving and increasing the bioaccessibility of phenolic compounds. The study reported herein aimed at elucidating the changes occurring in the soluble-free, soluble-conjugated and insoluble phenolic compositions caused by the processing of raw flours to broas, and the potential implications on their bioaccessibility, bioavailability and bioactivity.

\section{Materials and Methods}

\subsection{Reagents}

The reagents and commercial standards used for chromatographic analysis were described elsewhere [11]. Additionally, Folin-Ciocalteu reagent, sodium carbonate, 2' $2^{\prime}$ azobis-(2-amidinopropane) dihydrochloride (AAPH), Trolox and fluorescein sodium salt were obtained from Sigma-Aldrich, St. Louis, MO, USA.

\subsection{Maize Flour and Broas Preparation}

Five traditional Portuguese open-pollinated maize varieties (Broa-213, Pigarro, Castro Verde, Verdeal de Aperrela, Fandango) (Table S1), and their corresponding broas were studied. All maize samples were obtained from controlled trials conducted at ESAC (Escola Superior Agrária de Coimbra) and flours were obtained after milling the grain in an artisan water-mill with millstones (Moinhos do Inferno, Viseu, Falling Number 3100). A commercial hybrid maize flour, commonly used for broa production (Nacional Type 175) was also included in the study for comparison. This flour was acquired already milled and is described elsewhere [2]. Broas were prepared in a bakery following a traditional recipe [14]. The ingredients included 70\% maize flour, 20\% commercial rye flour (Concordia type 70 , Portugal) and $10 \%$ commercial wheat flour (National type 65, Portugal). Before extraction of phenolic compounds, broas were milled using a grinding mill (IKA MF 10.2, Königswinter, Germany) with a $1.5 \mathrm{~mm}$ sieve. The commercial rye and wheat flours used for broa production were also analyzed.

\subsection{Preparation of Phenolic Fractions}

Cereal flours (maize, rye and wheat) and broas ( $4 \mathrm{~g}$ ) were submitted to a conventional extraction procedure [11] with $20 \mathrm{~mL}$ of $\mathrm{EtOH} / \mathrm{H}_{2} \mathrm{O}(50 \%, v / v)$, to obtain an ethanolic 
solution containing the soluble phenolic compounds and a solid residue comprising the insoluble compounds. Alkaline hydrolyses were applied to both the ethanolic solution and residue. Three phenolic fractions were obtained: the soluble (SF), the soluble-hydrolyzed (SHF) and the insoluble (IF) fractions (Figure 1). The abbreviations used throughout the paper, including tables and figures, are listed in Table 1.

Table 1. List of abbreviations.

\begin{tabular}{|c|c|c|c|}
\hline Abbreviation & Definition & Abbreviation & Definition \\
\hline 55DFA & 5-5'-Dehydrodiferulic acid & Fan & Fandango \\
\hline 85DFA & 8-5'-Dehydrodiferulic acid & GAE & Gallic acid equivalents \\
\hline 8O4DFA & 8-O-4'-Dehydrodiferulic acid & HCAAs & Hydroxycinnamic acid amides \\
\hline AA & Antioxidant activity & HPLC & High performance liquid chromatography \\
\hline $\mathrm{AAi}$ & Insoluble antioxidant activity & IF & Insoluble fraction \\
\hline AAs & Soluble antioxidant activity & LOD & Limit of detection \\
\hline $\mathrm{B} 213$ & Broa 213 & LOQ & Limit of quantification \\
\hline CFP & Coumaroyl feruloyl putrescine & $\mathrm{n} / \mathrm{a}$ & Not applicable \\
\hline Com & Commercial & ORAC & Oxygen radical absorbance capacity \\
\hline $\mathrm{CV}$ & Castro Verde & PC & Phenolic content \\
\hline DAD & Diode array detector & PCi & Insoluble phenolic content \\
\hline DCS & Dicoumaroyl spermidine & PCs & Soluble phenolic content \\
\hline DFAs & Dehydrodiferulic acids & $\mathrm{pCA}$ & $p$-Coumaric acid \\
\hline DFP & Diferuloyl putrescine & pCAc & Soluble-conjugated $p$-coumaric acid \\
\hline $\mathrm{dw}$ & Dry weight & pCAf & Soluble-free $p$-coumaric acid \\
\hline ED & Electrochemical detector & pCAi & Insoluble $p$-coumaric acid \\
\hline EtOAC & Ethyl acetate & PCA & Principal component analysis \\
\hline $\mathrm{EtOH}$ & Ethanol & Pig & Pigarro \\
\hline FA & Ferulic acid & $\mathrm{SF}$ & Soluble fraction \\
\hline FAc & Soluble-conjugated ferulic acid & SHF & Soluble-hydrolyzed fraction \\
\hline FAE & Ferulic acid equivalents & TE & Trolox equivalents \\
\hline FAf & Soluble-free ferulic acid & VA & Verdeal de Aperrela \\
\hline FAi & Insoluble ferulic acid & & \\
\hline
\end{tabular}

Briefly, in order to obtain the soluble fraction (SF), the $\mathrm{pH}$ of the ethanolic solution $(5 \mathrm{~mL}$ ) was adjusted to $1.5 \pm 0.5$ with concentrated $\mathrm{HCl}$, followed by a liquid-liquid extraction with ethyl acetate (EtOAc, $3 \times 7.5 \mathrm{~mL}$ ). The combined EtOAc fractions were evaporated until dry and reconstituted in $5 \mathrm{~mL}$ of $\mathrm{EtOH} 50 \%$. To obtain the solublehydrolyzed fraction (SHF), the ethanolic solution $(5 \mathrm{~mL})$ was hydrolyzed with $\mathrm{NaOH} 4 \mathrm{M}$ (40 mL, pH $14 \pm 0.5$ ), under $\mathrm{N}_{2}$, for $15 \mathrm{~h}$, at room temperature [15,16]. After hydrolysis, the $\mathrm{pH}$ was set to $1.5 \pm 0.5$ with concentrated $\mathrm{HCl}$, and the phenolic compounds were extracted with EtOAc $(3 \times 30 \mathrm{~mL})$. The combined EtOAc fractions were evaporated until dry and reconstituted in $5 \mathrm{~mL}$ of $\mathrm{EtOH} 50 \%$.

The insoluble fraction (IF) was prepared from the solid residue, which was defatted with hexane $(3 \times 20 \mathrm{~mL})$ and centrifuged $(7000 \times g, 10 \mathrm{~min})$. The defatted residue was hydrolyzed with $\mathrm{NaOH} 4 \mathrm{M}(60 \mathrm{~mL}, \mathrm{pH} 14 \pm 0.5)$, for $15 \mathrm{~h}$ at room temperature, in the presence of $\mathrm{N}_{2}$. The obtained solution was extracted with EtOAc $(3 \times 30 \mathrm{~mL})$, evaporated until dry and reconstituted in $20 \mathrm{~mL}$ of EtOH $50 \%$. All fractions (SF, SHF and IF) of cereal flours and broas were prepared in duplicate and kept at $-20{ }^{\circ} \mathrm{C}$ until analysis. 


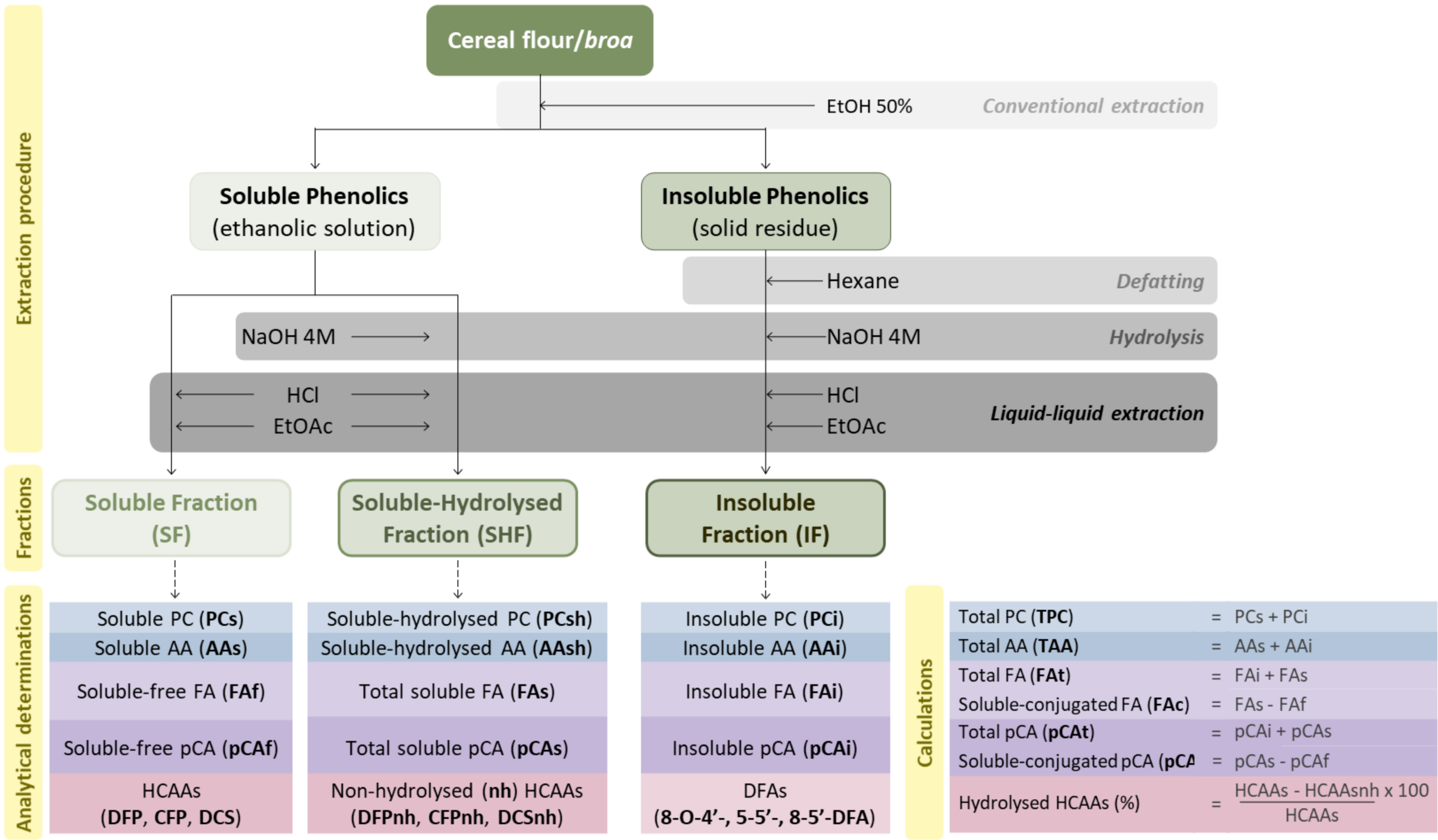

Figure 1. Representative scheme of the soluble (SF), soluble-hydrolyzed (SHF) and insoluble (IF) phenolic fractions and respective determinations. 


\subsection{Phenolic Content and Antioxidant Activity}

The phenolic content (PC) and antioxidant activity (AA) were determined in each fraction (Figure 1), using Folin-Ciocalteu and ORAC (oxygen radical absorbance capacity) assays, respectively, as previously reported [17]. Determinations were performed in triplicate and reported as mg GAE (gallic acid equivalents) and mmol of Trolox equivalents (TE) per $100 \mathrm{~g}$ of sample's dry weight $(\mathrm{dw})$, respectively. The total PC and the total AA were calculated as described in Figure 1.

\subsection{HPLC-DAD-ED Analysis}

Phenolic compounds were analyzed in a Thermo Fisher Scientific (Waltham, MS, USA) Surveyor high-performance liquid chromatography (HPLC) system, equipped with a diode array detector (DAD) programmed for scanning between 192 and $798 \mathrm{~nm}$ and an electrochemical detector, ED 40 Dionex (Sunnyvale, CA, USA). Analytical conditions for HPLC-DAD were previously reported [11]. In order to detect the phenolic compounds that could exhibit AA, electrochemical detection was programmed for a linear variation from -1.0 to $1.0 \mathrm{~V}$ in $1.00 \mathrm{~s}$ (detection by integrated voltammetry using a cyclic variation of the potential). The measurements were taken with a $50 \mathrm{~Hz}$ frequency with an analogic/digital converter.

Hydroxycinnamic acids (FA and pCA) were quantitated in all fractions (SF, SHF and IF) using standard ethanolic solutions prepared from the corresponding commercial standards, at $320 \mathrm{~nm}$, in a range from 0.15 to $100 \mathrm{mg} \mathrm{L}^{-1}\left(y=443378 x+1415.4, R^{2}=0.9989\right)$ and from 0.3 to $50 \mathrm{mg} \mathrm{L}^{-1}\left(y=624015 x-6094.7, R^{2}=0.9998\right)$, respectively. The major phenolic compounds (dehydrodiferulic acids and hydroxycinnamic acid amides) were previously identified by HPLC-DAD-MS/MS [11]. Due to the absence of commercially available standards, dehydrodiferulic acids, feruloyl putrescine and coumaroyl feruloyl putrescine were quantitated as FA equivalents (FAE) and dicoumaroyl spermidine was

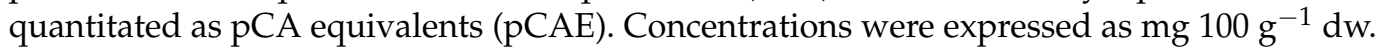

Limits of quantitation and detection (LOQ and LOD, signal to noise ratio $(\mathrm{S} / \mathrm{N})$ of 10 and 3, respectively) of FA and pCA were determined and confirmed by analyzing five independent solutions corresponding to these concentrations. The LOQ for both compounds corresponded to $0.05 \mathrm{mg} \mathrm{L}^{-1}$ (approximately $0.03 \mathrm{mg} 100 \mathrm{~g}^{-1} \mathrm{dw}$ ) and the LOD to $0.02 \mathrm{mg} \mathrm{L}^{-1}\left(0.01 \mathrm{mg} 100 \mathrm{~g}^{-1} \mathrm{dw}\right)$. In order to control the signal of both detectors (DAD and ED), standard mixtures of FA and pCA at $20 \mathrm{mg} \mathrm{L}^{-1}$ were analyzed after every fifteen injections. The total and soluble-conjugated pCA and FA contents were calculated as described in Figure 1.

\subsection{Data Analysis}

ChromQuest (version 3.1.6) software, Thermo Fisher Scientific, Waltham, MA, USA and 4880 software (Unicam, Lisbon, Portugal) were used for data acquisition and treatment of HPLC-DAD and ED analyses, respectively. The identification of pCA and FA was performed by comparison with standard solutions using commercially available standards and the identification of the main dehydrodiferulic acids and hydroxycinnamic acid amides was based on results previously reported [11]. For quantitative data analyses, the limit of significance was set at $p<0.05$. Paired-samples $t$-tests, independent-samples $t$-tests, ANOVA followed by post hoc Tukey tests, principal component analyses (PCA) and Pearson's coefficient correlations were obtained using the software SPSS version 21 (IBM, NY, USA).

\section{Results and Discussion}

Maize-based foods can be considered important sources of phenolic compounds in a balanced diet. Broas are usually prepared using open-pollinated traditional maize varieties but, more recently, hybrid maize varieties have allowed their production on a larger scale. This work intended to study the total (soluble and insoluble) phenolic composition of five Portuguese traditional maize varieties, which were cultivated in the same environment 
and in the same period of time, and the corresponding broas, contributing to a better understanding of the effect of processing on their bioaccessibility. A commercial maize flour and broa were also studied for comparison. As rye and wheat flours were used in broas recipes, these flours were also characterized. To achieve these goals, for each cereal flour and broa sample, three phenolic fractions were prepared according to Figure 1, namely, the soluble (SF), the soluble-hydrolyzed (SHF) and the insoluble (IF) fractions. The abbreviations used throughout the paper, including tables and figures, are listed in Table 1.

\subsection{Phenolic Content and Antioxidant Activity of Cereal Flours}

The results from the phenolic characterization, phenolic content (PC) and antioxidant activity (AA) of the different cereal flours used in the production of broas are presented in Table 2.

The total PC of maize flours ranged from 150 to $276 \mathrm{mg}$ GAE $100 \mathrm{~g}^{-1} \mathrm{dw}$. These values are according to those already described for maize [18-22] but, as expected, are lower than the values reported for pigmented (red, purple, blue or black) varieties (up to $3400 \mathrm{mg} \mathrm{GAE} 100 \mathrm{~g}^{-1} \mathrm{dw}$ in purple maize), due to the absence of anthocyanins and other flavonoids $[19,23]$. For the total AA, values ranged from 3.39 to 6.39 mmol TE $100 \mathrm{~g}^{-1} \mathrm{dw}$, which are within the range of the values described in the literature $[20,21,23]$. The insoluble compounds were responsible for the majority of maize flours' PC and AA $(82.5 \pm 3.9 \%$ and $85.3 \pm 3.3 \%$, respectively) (Table 2 ).

A strong and positive correlation was observed between insoluble AA and PC $(R=0.902$, $p<0.05)$ and between soluble AA and PC $(R=0.863, p<0.05)$ (Table 3$)$. These results were expected, as the PC has been described as one of the most important contributors to the AA of cereal grains [23].

The hydrolysis of the SF is usually performed to quantitate the total soluble and conjugated major phenolic acids of maize $[18,24,25]$. In the present work, the AA and PC were also measured in the SHF (Table 2), in order to evaluate the effect of the hydrolysis procedure on the soluble phenolics and associated AA. The hydrolysis of maize soluble phenolics (from SF to SHF) caused an increase $(115 \pm 45 \%)$ in their AA $(t=16.5$, $p<0.001$ ) (Table S2), suggesting that the hydrolyzed phenolic compounds exhibited a higher AA. Similarly, the PC increased by around $16 \pm 7 \%(t=6.96, p<0.001)$ after hydrolysis (Table S2), suggesting that this procedure influenced the content of interfering compounds, such as sugars, tyrosine or ascorbic acid, which can influence the PC determined by the Folin-Ciocalteu assay [26]. These findings show the importance of choosing other methods of analysis which can complement the global methods and give more detailed information, enabling the identification and quantitation of individual phenolics. Therefore, HPLC-DAD-ED analyses were performed in all fractions, allowing the quantitation of soluble-free, soluble-conjugated and insoluble ferulic (FA) and $p$-coumaric (pCA) acids and insoluble dehydrodiferulic acids (Figure 1), as previously described for other cereal-based foods [18,24,25]. Additionally, since free and conjugated phenolics may exhibit different antioxidant activities and health effects [7,10], the major soluble-conjugated hydroxycinnamic acids derivatives (hydroxycinnamic acid amides), which are readily available for absorption after consumption, were also quantitated (Figure 1). Moreover, the HPLC-ED analysis allowed the detection of compounds that can have antioxidant potential due to their free radical scavenger ability $[27,28]$. These results were compared with the AA obtained by the ORAC assay, which evaluates the AA against peroxyl radicals [17]. 


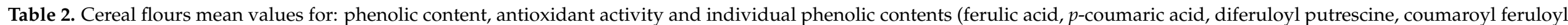

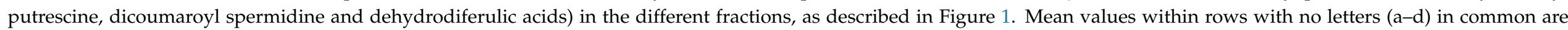
significantly different $(p<0.05)$.

\begin{tabular}{|c|c|c|c|c|c|c|c|c|c|c|}
\hline \multirow[b]{2}{*}{ Description } & \multirow[b]{2}{*}{ Phenolic Fraction } & \multicolumn{7}{|c|}{ Maize } & \multirow[b]{2}{*}{ Wheat } & \multirow[b]{2}{*}{ Rye } \\
\hline & & Broa-213 & Pigarro & Castro Verde & $\begin{array}{c}\text { Verdeal de } \\
\text { Aperrela }\end{array}$ & Fandango & Commercial & Average & & \\
\hline & & \multicolumn{9}{|c|}{ Phenolic Content (PC) (mg GAE $\left.100 \mathrm{~g}^{-1} \mathrm{dw}\right)$} \\
\hline Soluble & $\mathrm{SF}$ & $47.9 \pm 2.3^{\mathrm{a}}$ & $37.0 \pm 0.9^{\mathrm{ab}}$ & $37.9 \pm 5.1^{\mathrm{ab}}$ & $41.7 \pm 2.0^{\mathrm{ab}}$ & $37.1 \pm 2.5^{\mathrm{ab}}$ & $32.2 \pm 3.1^{b}$ & $39.0 \pm 5.3$ & $5.73 \pm 0.1$ & $15.9 \pm 0.9$ \\
\hline Soluble-hydrolyzed & SHF & $52.2 \pm 1.9^{a b}$ & $42.6 \pm 1.4^{\mathrm{ab}}$ & $42.6 \pm 4.9^{\mathrm{ab}}$ & $53.0 \pm 3.3^{a}$ & $41.0 \pm 2.2^{\mathrm{ab}}$ & $39.2 \pm 3.0^{b}$ & $45.1 \pm 6.0$ & $6.87 \pm 0.5$ & $17.1 \pm 1.0$ \\
\hline Insoluble & IF & $157 \pm 8.4^{\mathrm{ab}}$ & $200 \pm 19.4^{\mathrm{ac}}$ & $203 \pm 9.25^{\mathrm{ac}}$ & $226 \pm 22.7^{a c}$ & $239 \pm 17.6^{c}$ & $118 \pm 9.0^{b}$ & $190 \pm 45.3$ & $12.3 \pm 1.0$ & $27.6 \pm 0.7$ \\
\hline Total & $\mathrm{SF}+\mathrm{IF}$ & $205 \pm 10.7^{\mathrm{ab}}$ & $237 \pm 20.3^{\mathrm{ac}}$ & $240 \pm 14.4^{\mathrm{ac}}$ & $268 \pm 24.7^{\mathrm{ac}}$ & $276 \pm 20.1^{\mathrm{c}}$ & $150 \pm 12.1^{b}$ & $229 \pm 46.4$ & $18.0 \pm 1.1$ & $43.5 \pm 1.6$ \\
\hline \multirow[t]{2}{*}{ \% Insoluble } & $\mathrm{n} / \mathrm{a}$ & 76.6 & 84.4 & 84.3 & 84.5 & 86.6 & 78.5 & $82.5 \pm 3.9$ & 68.1 & 63.4 \\
\hline & & \multicolumn{9}{|c|}{ Antioxidant Activity (AA) (mmol TE $\left.100 \mathrm{~g}^{-1} \mathrm{dw}\right)$} \\
\hline Soluble & $\mathrm{SF}$ & $0.87 \pm 0.05^{\mathrm{a}}$ & $0.75 \pm 0.11^{\mathrm{a}}$ & $0.75 \pm 0.18^{a}$ & $0.72 \pm 0.08^{a}$ & $0.66 \pm 0.07^{a}$ & $0.46 \pm 0.04^{a}$ & $0.70 \pm 0.14$ & $0.17 \pm 0.02$ & $0.42 \pm 0.03$ \\
\hline Soluble-hydrolyzed & SHF & $1.65 \pm 0.08^{\mathrm{a}}$ & $1.59 \pm 0.20^{\mathrm{a}}$ & $1.28 \pm 0.20^{\mathrm{a}}$ & $1.39 \pm 0.33^{a}$ & $1.51 \pm 0.15^{\mathrm{a}}$ & $1.38 \pm 0.11^{\mathrm{a}}$ & $1.47 \pm 0.14$ & $0.13 \pm 0.02$ & $0.47 \pm 0.07$ \\
\hline Insoluble & IF & $3.40 \pm 0.24^{\mathrm{ab}}$ & $4.66 \pm 0.71 \mathrm{ab}$ & $4.02 \pm 0.44^{\mathrm{ab}}$ & $4.38 \pm 0.73^{a b}$ & $5.73 \pm 0.80^{\mathrm{a}}$ & $2.93 \pm 0.48^{b}$ & $4.19 \pm 0.99$ & $0.30 \pm 0.02$ & $0.62 \pm 0.07$ \\
\hline Total & $\mathrm{SF}+\mathrm{IF}$ & $4.27 \pm 0.29 \mathrm{ab}$ & $5.41 \pm 0.83^{\mathrm{ab}}$ & $4.76 \pm 0.61^{\mathrm{ab}}$ & $5.10 \pm 0.81^{\mathrm{ab}}$ & $6.39 \pm 0.88^{a}$ & $3.39 \pm 0.52^{b}$ & $4.89 \pm 1.02$ & $0.47 \pm 0.04$ & $1.03 \pm 0.10$ \\
\hline \multirow[t]{2}{*}{$\%$ Insoluble } & $\mathrm{n} / \mathrm{a}$ & 79.6 & 86.2 & 84.3 & 85.8 & 89.7 & 86.3 & $85.3 \pm 3.3$ & 63.7 & 59.6 \\
\hline & & \multicolumn{9}{|c|}{ Ferulic acid (FA) (mg $\left.100 \mathrm{~g}^{-1} \mathrm{dw}\right)$ and contribution (\%) for the total FA (bold) } \\
\hline Soluble-conjugated & SHF-SF & $\begin{array}{c}6.49 \pm 0.00^{\mathrm{a}} \\
\mathbf{( 6 . 3 )}\end{array}$ & $\begin{array}{c}5.80 \pm 1.44^{\mathrm{a}} \\
\mathbf{( 4 . 5 )}^{-}\end{array}$ & $\begin{array}{c}4.57 \pm 2.33^{a} \\
\text { (3.6) }\end{array}$ & $\begin{array}{c}6.66 \pm 0.43^{\mathrm{a}} \\
(4.5)\end{array}$ & $\begin{array}{c}5.21 \pm 0.51^{\mathrm{a}} \\
\text { (3.3) }\end{array}$ & $\begin{array}{c}5.32 \pm 0.13^{\mathrm{a}} \\
\mathbf{( 7 . 1 )}\end{array}$ & $\begin{array}{l}5.67 \pm 0.80 \\
\quad(4.9)\end{array}$ & $\begin{array}{l}0.25 \pm 0.02 \\
\quad(\mathbf{7 . 3 )}\end{array}$ & $\begin{array}{c}1.08 \pm 0.00 \\
\quad \mathbf{( 1 4 . 9 )}\end{array}$ \\
\hline Total soluble & SHF & $\begin{array}{c}6.84 \pm 0.02^{\mathrm{a}} \\
\mathbf{( 6 . 6 )}\end{array}$ & $\begin{array}{c}6.04 \pm 1.43^{\mathrm{a}} \\
(\mathbf{4} .7)\end{array}$ & $\begin{array}{c}4.81 \pm 2.38^{\mathrm{a}} \\
\mathbf{( 3 . 8 )}\end{array}$ & $\begin{array}{c}6.95 \pm 0.49^{\mathrm{a}} \\
\mathbf{( 4 . 7 )}\end{array}$ & $\begin{array}{c}5.44 \pm 0.53^{\mathrm{a}} \\
\quad \text { (3.4) }\end{array}$ & $\begin{array}{c}5.49 \pm 0.10^{\mathrm{a}} \\
\mathbf{( 7 . 3 )}\end{array}$ & $\begin{array}{c}5.93 \pm 0.84 \\
\quad(\mathbf{5 . 1})\end{array}$ & $\begin{array}{c}0.35 \pm 0.03 \\
\quad(\mathbf{1 0 . 3 )}\end{array}$ & $\begin{array}{c}1.34 \pm 0.01 \\
\mathbf{( 1 8 . 5 )}\end{array}$ \\
\hline Insoluble & IF & $\begin{array}{c}95.8 \pm 14.0^{\mathrm{ab}} \\
(\mathbf{9 3 . 3 )}\end{array}$ & $\begin{array}{c}122 \pm 18.0^{a b c} \\
(\mathbf{9 5 . 3 )}\end{array}$ & $\begin{array}{c}122 \pm 10.0^{a b c} \\
(\mathbf{9 6 . 2 )}\end{array}$ & $\begin{array}{c}143 \pm 21.6^{b c} \\
(\mathbf{9 5 . 4 )}\end{array}$ & $\begin{array}{c}152 \pm 7.2^{c} \\
(\mathbf{9 6} .5)\end{array}$ & $\begin{array}{c}69.6 \pm 2.32^{\mathrm{a}} \\
\quad(\mathbf{9 2 . 7 )}\end{array}$ & $\begin{array}{c}117 \pm 30.4 \\
\mathbf{( 9 4 . 9 )}\end{array}$ & $\begin{array}{c}3.04 \pm 0.24 \\
\quad(89.7)\end{array}$ & $\begin{array}{l}5.92 \pm 0.49 \\
\quad \mathbf{( 8 1 . 6 )}\end{array}$ \\
\hline Total & $\mathrm{SHF}+\mathrm{IF}$ & $103 \pm 14.0^{\mathrm{ab}}$ & $128 \pm 19.4^{\mathrm{ab}}$ & $127 \pm 12.3^{\mathrm{ab}}$ & $150 \pm 21.1^{\mathrm{a}}$ & $157 \pm 7.8^{\mathrm{a}}$ & $75.1 \pm 2.2^{b}$ & $123 \pm 31.5$ & $3.39 \pm 0.20$ & $7.26 \pm 0.50$ \\
\hline
\end{tabular}


Table 2. Cont

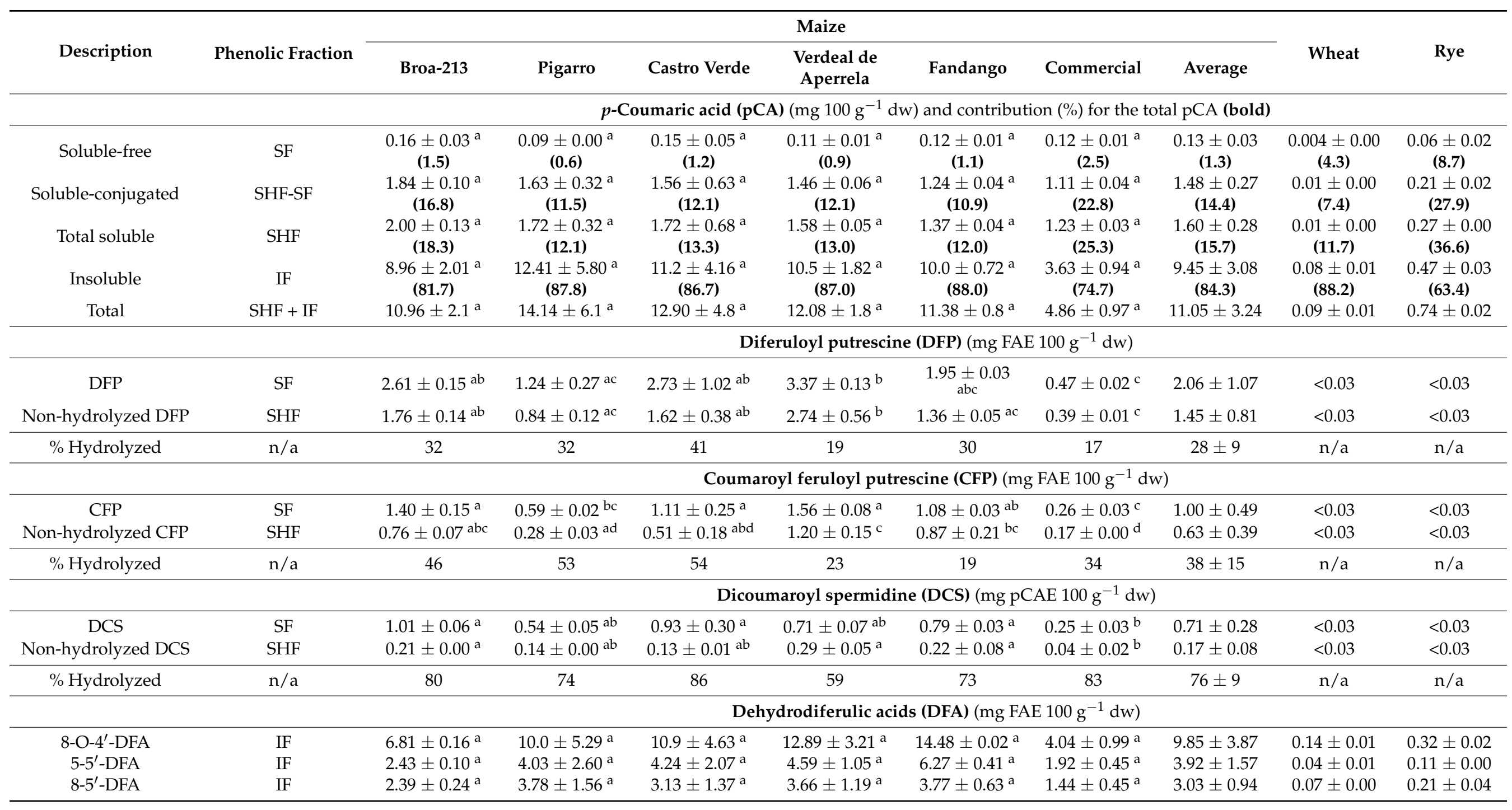




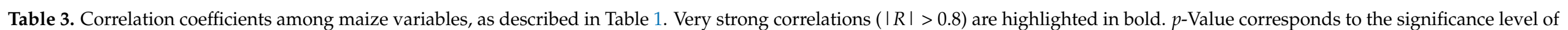
Pearson correlation coefficient indicated as *: significant at $p<0.05 ;{ }^{* *}$ : significant at $p<0.01$.

\begin{tabular}{|c|c|c|c|c|c|c|c|c|c|c|c|c|c|c|c|c|c|}
\hline & & \multicolumn{7}{|c|}{ SF } & \multicolumn{2}{|c|}{ SHF-SF } & \multicolumn{7}{|c|}{ IF } \\
\hline & & PCs & AAs & FAf & pCAf & DFP & CFP & DCS & FAc & pCAc & PCi & AAi & FAi & pCAi & 8O4DFA & 55DFA & 85DFA \\
\hline \multirow{7}{*}{ SF } & PCs & & $0.863 *$ & $0.996^{* *}$ & 0.521 & 0.715 & $0.813 *$ & 0.776 & 0.665 & 0.810 & 0.137 & -0.065 & 0.146 & 0.352 & 0.097 & -0.073 & 0.147 \\
\hline & AAs & & & 0.887 * & 0.368 & 0.687 & 0.716 & $0.846^{*}$ & 0.403 & 0.939 ** & 0.375 & 0.185 & 0.356 & 0.731 & 0.306 & 0.154 & 0.460 \\
\hline & FAf & & & & 0.494 & 0.743 & 0.821 * & 0.779 & 0.663 & 0.841 * & 0.162 & -0.065 & 0.166 & 0.404 & 0.116 & -0.066 & 0.184 \\
\hline & pCAf & & & & & 0.388 & 0.409 & 0.664 & -0.136 & 0.369 & -0.275 & -0.413 & -0.283 & -0.168 & -0.253 & -0.295 & -0.420 \\
\hline & DFP & & & & & & $0.966^{* *}$ & 0.794 & 0.354 & 0.506 & 0.578 & 0.219 & 0.572 & 0.551 & 0.562 & 0.371 & 0.472 \\
\hline & CFP & & & & & & & 0.822 * & 0.472 & 0.512 & 0.556 & 0.262 & 0.565 & 0.492 & 0.547 & 0.373 & 0.447 \\
\hline & DCS & & & & & & & & 0.096 & 0.680 & 0.451 & 0.254 & 0.439 & 0.575 & 0.434 & 0.327 & 0.376 \\
\hline \multirow{2}{*}{ SHF-SF } & FAc & & & & & & & & & 0.420 & -0.004 & -0.120 & 0.029 & 0.072 & -0.044 & -0.203 & 0.080 \\
\hline & pCAc & & & & & & & & & & 0.082 & -0.102 & 0.055 & 0.588 & -0.002 & -0.159 & 0.230 \\
\hline \multirow{7}{*}{ IF } & PCi & & & & & & & & & & & $0.902 *$ & $0.998^{* *}$ & 0.794 & $0.994^{* *}$ & 0.950 ** & 0.952 ** \\
\hline & $\mathbf{A A i}$ & & & & & & & & & & & & 0.912 * & 0.652 & 0.909 * & $0.961^{* *}$ & 0.882 * \\
\hline & FAi & & & & & & & & & & & & & 0.762 & $0.996^{* *}$ & $0.955^{* *}$ & $0.942^{\text {** }}$ \\
\hline & pCAi & & & & & & & & & & & & & & 0.729 & 0.633 & 0.898 * \\
\hline & 8O4DFA & & & & & & & & & & & & & & & $0.970 * *$ & $0.918^{* *}$ \\
\hline & 55DFA & & & & & & & & & & & & & & & & 0.866 * \\
\hline & 85DFA & & & & & & & & & & & & & & & & \\
\hline
\end{tabular}


The results obtained for maize flours (Table 2) show that the total FA and pCA contents

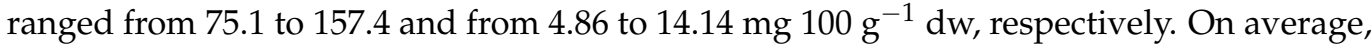
$94.9 \%$ of total FA and $84.3 \%$ of total pCA of maize flours were present in their insoluble form. Only around $0.2 \%$ of the total FA and $1.3 \%$ of total pCA were in their soluble-free forms, while $4.9 \%$ of total FA and $14.4 \%$ of total pCA were soluble, but conjugated with other compounds (soluble-conjugated) (Table 2). These results are also according to the literature [4,18-23,29-31].

FA and pCA are known to have antioxidant characteristics $[27,28]$ and were detected, as expected, by HPLC-ED analysis. Additionally, maize FA content strongly influenced the AA determined by the ORAC assay, since strong positive correlations were found between AA and FA in both SF and IF ( $R>0.8, p<0.05)$ (Table 3). Insoluble FA was responsible for $43.6 \pm 4.9 \%$ of maize insoluble AA (Table S3). Contrastingly, only around $0.6 \pm 0.1 \%$ of soluble-free FA and $0.4 \pm 0.1 \%$ of soluble-free pCA were responsible for maize soluble AA (Table S3). Thus, soluble-free phenolics were not the main contributors of maize soluble AA. Instead, hydroxycinnamic acid amides, which include diferuloyl putrescine, coumaroyl feruloyl putrescine and dicoumaroyl spermidine, the major soluble phenolic compounds present in maize flours (Table 2), can be the main contributors to maize AA.

The trans-unsaturated compounds can isomerize into the cis form by daylight or during the extraction procedure [4]. As previously reported [11], all the isomeric forms (cis/cis, cis/trans and trans/trans) of diferuloyl putrescine, coumaroyl feruloyl putrescine and dicoumaroyl spermidine were detected in the SF of maize, but the cis isomers were only present in trace amounts, below the LOQ of the analytical method $(0.03 \mathrm{mg}$ FA $/ \mathrm{pCA}$ $100 \mathrm{~g}^{-1} \mathrm{dw}$ ). Therefore, in this work, hydroxycinnamic acid amides were quantitated considering the sum of all corresponding isomeric forms which were above the LOQ.

The SHF showed higher $(p<0.01)$ amounts of FA and pCA and lower $(p<0.01)$ amounts of hydroxycinnamic acid amides than the SF (Table 2), which indicated that FA and pCA were released from hydroxycinnamic acid amides during the hydrolysis procedure of the soluble phenolics (Figure 1). The higher amounts in free phenolic acids can also explain the higher AA values obtained for the SHF, suggesting that free FA and pCA are more efficient than hydroxycinnamic acid amides in inhibiting the oxidation induced by peroxyl radicals [17]. Nevertheless, dicoumaroyl spermidine, the most abundant conjugated form of $\mathrm{pCA}$, also contributed for the soluble AA, since very strong and positive correlations were found between the soluble AA with both conjugated pCA $(R=0.939, p<0.01)$ and dicoumaroyl spermidine $(R=0.846, p<0.05)$ (Table 3). Additionally, the ED analysis showed that diferuloyl putrescine exhibited an antioxidant radical-scavenging activity linked to their hydrogen- or electron-donating ability [27,28]. Indeed, it has been reported that hydroxycinnamic acid amides are also potent antioxidants and that feruloyl derivatives exhibited higher radical scavenging activities linked to their hydrogen- or electron-donating ability than soluble-free FA [7].

Maize flours' SHF still presented considerable amounts of hydroxycinnamic acid amides (Table 2), since only around $28 \pm 9 \%$ of diferuloyl putrescine, $38 \pm 15 \%$ of coumaroyl feruloyl putrescine and $76 \pm 9 \%$ of dicoumaroyl spermidine were hydrolyzed (Table 2). As it has been reported [32], hydroxycinnamic acid amides are difficult to extract quantitatively. Therefore, it is possible that the contents of maize soluble-conjugated FA and pCA have been underestimated.

Other abundant phenolic compounds detected in maize were dehydrodiferulic acids, such as $8-O-4^{\prime}$-dehydrodiferulic acid, followed by $5-5^{\prime}$ - and $8-5^{\prime}$-dehydrodiferulic acids (Table 2), which were only detected in maize IF, since they are bound to arabinoxylans $[4,5,10]$. The most abundant dehydrodiferulic acid $\left(8-\mathrm{O}-4^{\prime}-\right)$ was electrochemically active and therefore showed AA linked to their hydrogen- or electron-donating ability. Additionally, all three main dehydrodiferulic acids showed very strong and positive correlations with the insoluble AA determined by the ORAC assay $(R>0.88, p<0.05)$ and insoluble PC $(R>0.95$, $p<0.01$ ) (Table 3), which suggests they can be important contributors for maize AA against 
peroxyl radicals and PC. It has also been reported that dehydrodiferulic acids show higher radical-scavenging efficacies than FA [33].

Very strong and positive correlations were also found among maize insoluble FA and the three main dehydrodiferulic acids $(R>0.87, p<0.05)$, between dicoumaroyl spermidine and coumaroyl feruloyl putrescine $(R=0.822, p<0.05)$ and coumaroyl feruloyl putrescine and diferuloyl putrescine $(R=0.966, p<0.01)$ (Table 3$)$. A possible explanation for these correlations could be the different levels of biotic and abiotic stresses that the plants had been exposed, such as drought or salt stress, which are known to increase the content in phenolic acids [4,34]. However, the commercial maize was the only variety which had been exposed to a different environment, and therefore differences in maize genotypes may be the main responsible for the results observed. Indeed, when considering only the traditional samples ( $n=5$, data not shown), which had been submitted to the same edaphoclimatic and agronomic conditions, similar correlations were found, namely, between diferuloyl putrescine and coumaroyl feruloyl putrescine $(R=0.927, p<0.05), 5-5^{\prime}$-dehydrodiferulic acid and dicoumaroyl spermidine $(R=0.982, p<0.01), 8-O-4^{\prime}-$ and $5-5^{\prime}$ - dehydrodiferulic acids $(R=0.966, p<0.01)$, insoluble FA and 8-O- $4^{\prime}$-dehydrodiferulic acid $(R=0.994, p<0.01)$ and insoluble FA and 5-5'-dehydrodiferulic acid $(R=0.953, p<0.05)$. Therefore, maize samples with higher hydroxycinnamic acid amides, ferulic acid and dehydrodiferulic acids contents may indicate a higher genetic resistance or tolerance of the variety to biotic and abiotic stresses. Recently, Butts-Wilmsmeyer et al. (2020) [35] showed that, in maize, hydroxycinnamic acids contents are quantitative traits and may be influenced by the environment in which the plants have grown. Furthermore, dehydrodiferulic acids and hydroxycinnamic acid amides can both decrease pathogen penetration into plant tissues $[4,36]$.

As expected [4], when compared to maize, the rye and wheat flours used in broa recipes presented lower total $\mathrm{PC}$, total AA and individual phenolics $(p<0.01)$. Moreover, the contribution of the IF for the total PC and total AA was also smaller $(p<0.01)$, with values between 59.6 and $68.1 \%$ (Table 2).

\subsection{Phenolic Content and Antioxidant Activity of Broas}

The characterization of broas is presented in Table 4. Their total PC (159-223 mg GAE $100 \mathrm{~g}^{-1} \mathrm{dw}$ ) was similar to that reported for other maize-based food products, such as tortillas and tortilla chips $\left(60.7-207 \mathrm{mg}^{\left.100 \mathrm{~g}^{-1} \mathrm{dw}\right)}[18,21]\right.$. In particular, the FA and pCA

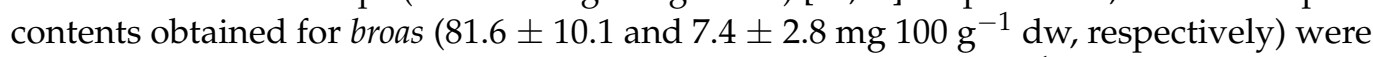
higher than the contents described for rye (54.0 and $2.8 \mathrm{mg} 100 \mathrm{~g}^{-1}$ ) and wheat (8.2 and $0.28 \mathrm{mg} 100 \mathrm{~g}^{-1}$ ) breads [37], possibly due to the higher phenolic contents of maize [4].

In broas, the IF was responsible for $71.6 \pm 3.0 \%$ of total PC and $77.9 \pm 1.9 \%$ of the total AA (Table 4). On average, $95.9 \%$ of total FA and $81.3 \%$ of total pCA of broas were present in their insoluble form. Only around $0.99 \%$ and $8.2 \%$ of the total FA and pCA, respectively, were in their soluble-free forms, whilst $3.7 \%$ of total FA and $10.9 \%$ of total pCA were soluble, but conjugated with other compounds (Table 4).

As for maize flours, hydroxycinnamic acid amides and dehydrodiferulic acids were detected as major phenolic compounds present in broas SF and IF, respectively (Table 4). Differences in the maize varieties used for broas production can explain the strong and positive correlations among the insoluble FA and dehydrodiferulic acids $(R>0.85, p<0.05)$, as well as between dicoumaroyl spermidine and dehydrodiferulic acids $(R>0.92, p<0.05)$ (Table 5). 


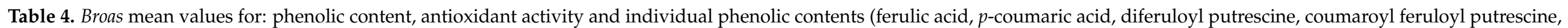

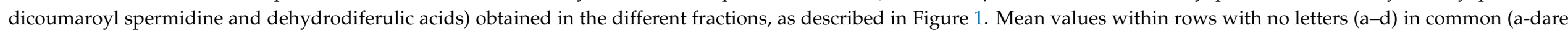
significantly different $(p<0.05)$.

\begin{tabular}{|c|c|c|c|c|c|c|c|c|}
\hline Description & $\begin{array}{l}\text { Phenolic } \\
\text { Fraction }\end{array}$ & Broa-213 & Pigarro & Castro Verde & $\begin{array}{c}\text { Verdeal de } \\
\text { Aperrela }\end{array}$ & Fandango & Commercial & Average \\
\hline \multicolumn{9}{|c|}{ Phenolic Content (PC) (mg GAE $\left.100 \mathrm{~g}^{-1} \mathrm{dw}\right)$} \\
\hline Soluble & $\mathrm{SF}$ & $56.9 \pm 3.0^{\mathrm{a}}$ & $53.5 \pm 2.7^{\mathrm{a}}$ & $53.2 \pm 3.7^{\mathrm{a}}$ & $58.1 \pm 2.3^{\mathrm{a}}$ & $59.8 \pm 1.2^{\mathrm{a}}$ & $52.1 \pm 5.6^{\mathrm{a}}$ & $55.6 \pm 3.1$ \\
\hline Soluble-hydrolyzed & SHF & $55.8 \pm 1.7^{\mathrm{a}}$ & $62.4 \pm 1.9 \mathrm{ab}$ & $67.8 \pm 2.0^{b}$ & $69.9 \pm 4.8^{b}$ & $55.6 \pm 1.0^{\mathrm{a}}$ & $52.1 \pm 1.7^{\mathrm{a}}$ & $60.6 \pm 7.2$ \\
\hline Insoluble & IF & $149 \pm 13.6^{a}$ & $169 \pm 4.22^{\mathrm{a}}$ & $144 \pm 6.50^{\mathrm{a}}$ & $138 \pm 2.69^{a b}$ & $145 \pm 10.5^{a}$ & $107 \pm 2.03^{b}$ & $142 \pm 20.4$ \\
\hline Total & $\mathrm{SF}+\mathrm{IF}$ & $206 \pm 16.6^{\mathrm{a}}$ & $223 \pm 6.92{ }^{a}$ & $198 \pm 10.2^{\mathrm{ab}}$ & $196 \pm 5.06^{\mathrm{ab}}$ & $205 \pm 11.8^{a}$ & $159 \pm 7.60^{b}$ & $197 \pm 21.3$ \\
\hline \% Insoluble & $\mathrm{n} / \mathrm{a}$ & 72.3 & 76 & 73.1 & 70.3 & 70.7 & 67.2 & $71.6 \pm 3.0$ \\
\hline \multicolumn{9}{|c|}{ Antioxidant Activity (AA) (mmol TE $\left.100 \mathrm{~g}^{-1} \mathrm{dw}\right)$} \\
\hline Soluble & SF & $0.99 \pm 0.07^{\mathrm{a}}$ & $0.92 \pm 0.07^{\mathrm{ab}}$ & $0.86 \pm 0.13^{\mathrm{ab}}$ & $0.90 \pm 0.18^{\mathrm{ab}}$ & $0.79 \pm 0.03^{b}$ & $0.54 \pm 0.03^{c}$ & $0.83 \pm 0.16$ \\
\hline Soluble-hydrolyzed & SHF & $1.22 \pm 0.13^{\mathrm{a}}$ & $1.28 \pm 0.12^{\mathrm{a}}$ & $1.39 \pm 0.26^{\mathrm{a}}$ & $1.23 \pm 0.12^{\mathrm{a}}$ & $0.92 \pm 0.19^{\mathrm{a}}$ & $1.04 \pm 0.00^{\mathrm{a}}$ & $1.18 \pm 0.17$ \\
\hline Insoluble & IF & $3.12 \pm 0.70^{\mathrm{a}}$ & $3.95 \pm 0.15^{\mathrm{a}}$ & $2.82 \pm 0.53^{\mathrm{ab}}$ & $3.20 \pm 0.16^{\mathrm{a}}$ & $2.94 \pm 0.13^{\mathrm{ab}}$ & $1.76 \pm 0.26^{b}$ & $2.97 \pm 0.71$ \\
\hline Total & $\mathrm{SF}+\mathrm{IF}$ & $4.11 \pm 0.77^{\mathrm{a}}$ & $4.87 \pm 0.22^{\mathrm{a}}$ & $3.68 \pm 0.65^{\mathrm{a}}$ & $4.10 \pm 0.35^{\mathrm{a}}$ & $3.73 \pm 0.16^{a}$ & $2.30 \pm 0.29^{b}$ & $3.80 \pm 0.85$ \\
\hline \% Insoluble & $\mathrm{n} / \mathrm{a}$ & 76 & 81.2 & 76.7 & 78.1 & 78.9 & 76.4 & $77.9 \pm 1.9$ \\
\hline \multicolumn{9}{|c|}{ Ferulic acid (FA) (mg $\left.100 \mathrm{~g}^{-1} \mathrm{dw}\right)$ and contribution (\%) for the total FA (bold) } \\
\hline Soluble-free & $\mathrm{SF}$ & $0.91 \pm 0.14^{\mathrm{a}}(\mathbf{0 . 9 7 )}$ & $0.80 \pm 0.24^{\mathrm{a}}(\mathbf{0 . 9 3})$ & $0.78 \pm 0.00^{\mathrm{a}} \mathbf{( 0 . 9 4 )}$ & $0.81 \pm 0.06^{\mathrm{a}} \mathbf{( 0 . 9 5 )}$ & $0.79 \pm 0.18^{\mathrm{a}} \mathbf{( 1 . 0 3 )}$ & $0.71 \pm 0.11^{\text {a }} \mathbf{( 1 . 1 0 )}$ & $0.80 \pm 0.07 \mathbf{( 0 . 9 9 )}$ \\
\hline Total soluble & SHF & $5.22 \pm 0.31^{\mathrm{a}}(\mathbf{5 . 3 )}$ & $3.23 \pm 0.08^{a}(3.8)$ & $4.08 \pm 1.09^{\text {a }}(\mathbf{4 . 9 )}$ & $3.68 \pm 1.40^{\mathrm{a}}(\mathbf{4 . 4 )}$ & $3.87 \pm 0.00^{\mathrm{a}}(\mathbf{4 . 8 )}$ & $3.18 \pm 0.53^{\mathrm{a}}(\mathbf{4 . 9 )}$ & $3.88 \pm 0.75$ \\
\hline Insoluble & IF & $89.3 \pm 0.1^{\mathrm{a}}(\mathbf{9 4 . 4 )}$ & $82.1 \pm 15.5^{\mathrm{a}} \mathbf{( 9 6 . 2 )}$ & $79.3 \pm 0.59^{a}(\mathbf{9 5 . 1})$ & $81.8 \pm 0.63^{a}(\mathbf{9 5 . 7 )}$ & $75.9 \pm 4.18^{a} \mathbf{( 9 5 . 2 )}$ & $61.4 \pm 18.2^{a}(\mathbf{9 5 . 1})$ & $78.27 \pm 9.4$ (95.9) \\
\hline Total & $\mathrm{SHF}+\mathrm{IF}$ & $94.5 \pm 2.62^{\mathrm{a}}$ & $85.3 \pm 15.38^{\mathrm{a}}$ & $83.3 \pm 0.51^{\mathrm{a}}$ & $85.5 \pm 0.78^{\mathrm{a}}$ & $79.8 \pm 1.95^{\mathrm{a}}$ & $64.5 \pm 17.69^{a}$ & $81.62 \pm 10.06$ \\
\hline \multicolumn{9}{|c|}{$p$-Coumaric acid (pCA) $\left(\mathrm{mg} 100 \mathrm{~g}^{-1} \mathrm{dw}\right)$ and contribution $(\%)$ for the total pCA (bold) } \\
\hline Soluble-free & SF & $0.66 \pm 0.03^{a}(7.4)$ & $0.57 \pm 0.09^{\mathrm{a}}(5.3)$ & $0.63 \pm 0.01^{\mathrm{a}}(6.9)$ & $0.54 \pm 0.03^{\mathrm{a}} \mathbf{( 7 . 6 )}$ & $0.53 \pm 0.17^{\mathrm{a}} \mathbf{( 1 0 . 4 )}$ & $0.39 \pm 0.03^{a}(\mathbf{1 1 . 7})$ & $0.55 \pm 0.09$ (8.2) \\
\hline Soluble-conjugated & SHF-SF & $1.06 \pm 0.09^{\mathrm{a}} \mathbf{( 1 1 . 8 )}$ & $0.53 \pm 0.00^{\mathrm{a}} \mathbf{( 4 . 9 )}$ & $0.82 \pm 0.33^{a}(\mathbf{9 . 0 )}$ & $0.59 \pm 0.34^{\mathrm{a}}(\mathbf{8 . 4 )}$ & $0.43 \pm 0.23^{\mathrm{a}} \mathbf{( 8 . 5 )}$ & $0.78 \pm 0.10^{a}(\mathbf{2 3 . 1})$ & $0.70 \pm 0.23$ (10.9) \\
\hline Total soluble & SHF & $1.72 \pm 0.06^{\mathrm{a}} \mathbf{( 1 9 . 2 )}$ & $1.10 \pm 0.09^{\mathrm{a}} \mathbf{( 1 0 . 2 )}$ & $1.45 \pm 0.34^{\mathrm{a}} \mathbf{( \mathbf { 1 5 . 9 ) }}$ & $1.13 \pm 0.31^{\mathrm{a}} \mathbf{( \mathbf { 1 6 . 0 } )}$ & $1.08 \pm 0.20^{\mathrm{a}} \mathbf{( 1 8 . 9 )}$ & $1.17 \pm 0.13^{\mathrm{a}}$ (34.8) & $1.28 \pm 0.26$ (19.2) \\
\hline Insoluble & IF & $7.30 \pm 0.1^{\mathrm{a}}(\mathbf{8 0 . 8 )}$ & $9.71 \pm 1.4^{\mathrm{a}} \mathbf{( 8 9 . 8 )}$ & $7.66 \pm 0.6^{a b}(\mathbf{8 4 . 1 )}$ & $5.92 \pm 0.0^{\mathrm{bc}}(\mathbf{8 3 . 9 )}$ & $4.23 \pm 0.3^{\mathrm{cd}}(\mathbf{8 1 . 1})$ & $2.20 \pm 0.48^{d}(\mathbf{6 5 . 2})$ & $6.17 \pm 2.67$ (81.3) \\
\hline Total & $\mathrm{SHF}+\mathrm{IF}$ & $9.03 \pm 0.23^{a b}$ & $10.80 \pm 1.34^{\mathrm{a}}$ & $9.11 \pm 0.28^{a b}$ & $7.05 \pm 0.33^{b}$ & $5.31 \pm 0.16^{\mathrm{bc}}$ & $3.36 \pm 0.36^{c}$ & $7.40 \pm 2.79$ \\
\hline
\end{tabular}


Table 4. Cont.

\begin{tabular}{|c|c|c|c|c|c|c|c|c|}
\hline Description & $\begin{array}{l}\text { Phenolic } \\
\text { Fraction }\end{array}$ & Broa-213 & Pigarro & Castro Verde & $\begin{array}{c}\text { Verdeal de } \\
\text { Aperrela }\end{array}$ & Fandango & Commercial & Average \\
\hline \multicolumn{9}{|c|}{ Diferuloyl putrescine (DFP) (mg FAE $\left.100 \mathrm{~g}^{-1} \mathrm{dw}\right)$} \\
\hline DFP & SF & $1.76 \pm 0.07^{\mathrm{a}}$ & $1.14 \pm 0.31^{\mathrm{a}}$ & $1.70 \pm 0.15^{\mathrm{a}}$ & $2.52 \pm 0.05^{b}$ & $1.34 \pm 0.15^{\mathrm{a}}$ & $0.38 \pm 0.05^{c}$ & $1.47 \pm 0.71$ \\
\hline Non-hydrolyzed DFP & SHF & $1.72 \pm 0.05^{\mathrm{ab}}$ & $0.75 \pm 0.08^{c}$ & $1.56 \pm 0.17^{\mathrm{ab}}$ & $1.87 \pm 0.46^{\mathrm{a}}$ & $0.99 \pm 0.01 \mathrm{bc}$ & $0.33 \pm 0.02^{c}$ & $1.20 \pm 0.61$ \\
\hline$\%$ Hydrolyzed & $\mathrm{n} / \mathrm{a}$ & 3 & 35 & 8 & 26 & 26 & 14 & $19 \pm 12$ \\
\hline \multicolumn{9}{|c|}{ Coumaroyl feruloyl putrescine (CFP) (mg FAE $\left.100 \mathrm{~g}^{-1} \mathrm{dw}\right)$} \\
\hline Non-hydrolyzed CFP & SHF & $0.64 \pm 0.003^{a}$ & $0.34 \pm 0.03 \mathrm{bc}$ & $0.59 \pm 0.07 \mathrm{ab}$ & $0.73 \pm 0.14^{\mathrm{a}}$ & $0.45 \pm 0.08^{a b}$ & $0.15 \pm 0.01^{\mathrm{c}}$ & $0.48 \pm 0.21$ \\
\hline \% Hydrolyzed & $\mathrm{n} / \mathrm{a}$ & 22 & 29 & 11 & 25 & 13 & 27 & $21 \pm 7$ \\
\hline \multicolumn{9}{|c|}{ Dicoumaroyl spermidine (DCS) (mg pCAE $\left.100 \mathrm{~g}^{-1} \mathrm{dw}\right)$} \\
\hline DCS & $\mathrm{SF}$ & $0.71 \pm 0.04^{\mathrm{a}}$ & $0.51 \pm 0.10^{\mathrm{ab}}$ & $0.64 \pm 0.04^{\mathrm{ab}}$ & $0.45 \pm 0.04^{b}$ & $0.48 \pm 0.07^{\mathrm{ab}}$ & $0.15 \pm 0.05^{c}$ & $0.49 \pm 0.19$ \\
\hline Non-hydrolyzed DCS & SHF & $0.10 \pm 0.04^{\mathrm{a}}$ & $0.07 \pm 0.002^{\mathrm{a}}$ & $0.09 \pm 0.004^{\mathrm{a}}$ & $0.09 \pm 0.01^{\mathrm{a}}$ & $0.10 \pm 0.02^{\mathrm{a}}$ & $0.05 \pm 0.0001^{\mathrm{a}}$ & $0.08 \pm 0.02$ \\
\hline \% Hydrolyzed & $\mathrm{n} / \mathrm{a}$ & 86 & 87 & 86 & 80 & 79 & 67 & $81 \pm 7$ \\
\hline \multicolumn{9}{|c|}{ Dehydrodiferulic acids (DFA) (mg FAE $100 \mathrm{~g}^{-1} \mathrm{dw}$ ) } \\
\hline 8-O-4'-DFA & IF & $8.42 \pm 0.08^{\mathrm{a}}$ & $6.88 \pm 1.09^{\mathrm{a}}$ & $7.62 \pm 0.73^{\mathrm{a}}$ & $6.72 \pm 1.14^{\mathrm{a}}$ & $6.09 \pm 0.05^{\mathrm{a}}$ & $3.04 \pm 0.20^{\mathrm{b}}$ & $6.46 \pm 1.86$ \\
\hline $5-5^{\prime}$-DFA & IF & $3.27 \pm 0.06^{\mathrm{a}}$ & $2.01 \pm 0.84^{\mathrm{ab}}$ & $3.03 \pm 0.34^{\mathrm{a}}$ & $2.60 \pm 0.45^{\mathrm{ab}}$ & $2.55 \pm 0.03^{a b}$ & $1.29 \pm 0.11^{b}$ & $2.46 \pm 0.72$ \\
\hline $8-5^{\prime}-\mathrm{DFA}$ & IF & $2.90 \pm 0.12^{\mathrm{a}}$ & $2.72 \pm 0.59^{a}$ & $2.84 \pm 0.34^{\mathrm{a}}$ & $2.60 \pm 0.25^{\mathrm{a}}$ & $2.43 \pm 0.09^{a}$ & $1.01 \pm 0.11^{\mathrm{b}}$ & $2.42 \pm 0.71$ \\
\hline
\end{tabular}




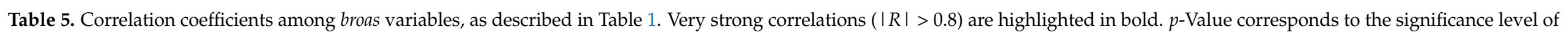
Pearson correlation coefficient indicated as *: significant at $p<0.05 ;{ }^{* *}$ : significant at $p<0.01$.

\begin{tabular}{|c|c|c|c|c|c|c|c|c|c|c|c|c|c|c|c|c|c|}
\hline & & \multicolumn{7}{|c|}{ SF } & \multicolumn{2}{|c|}{ SHF-SF } & \multicolumn{7}{|c|}{ IF } \\
\hline & & PCs & AAs & FAf & pCAf & DFP & CFP & DCS & FAc & pCAc & PCi & AAi & FAi & pCAi & 8O4DFA & 55DFA & 85DFA \\
\hline \multirow{7}{*}{ SF } & PCs & & 0.397 & 0.492 & 0.249 & 0.579 & 0.566 & 0.314 & 0.327 & -0.323 & 0.225 & 0.291 & 0.431 & -0.103 & 0.349 & 0.493 & 0.405 \\
\hline & AAs & & & 0.864 * & 0.908 * & 0.744 & 0.795 & 0.894 * & 0.566 & 0.141 & 0.830 * & 0.847 * & $0.993^{* *}$ & $0.832 *$ & $0.959 * *$ & 0.794 & $0.957^{* *}$ \\
\hline & FAf & & & & $0.818^{*}$ & 0.595 & 0.719 & $0.822 *$ & 0.826 * & 0.426 & 0.576 & 0.571 & 0.915 * & 0.545 & 0.845 * & 0.792 & 0.756 \\
\hline & pCAf & & & & & 0.620 & 0.678 & $0.995^{* *}$ & 0.737 & 0.362 & 0.736 & 0.642 & $0.918^{* *}$ & 0.783 & $0.986^{* *}$ & 0.910 * & $0.940 * *$ \\
\hline & DFP & & & & & & $0.981^{* *}$ & 0.608 & 0.437 & 0.025 & 0.369 & 0.493 & 0.735 & 0.400 & 0.715 & 0.750 & 0.734 \\
\hline & CFP & & & & & & & 0.663 & 0.564 & 0.173 & 0.377 & 0.494 & 0.802 & 0.426 & 0.763 & 0.792 & 0.746 \\
\hline & DCS & & & & & & & & 0.753 & 0.330 & 0.734 & 0.627 & $0.908^{*}$ & 0.742 & $0.981^{* *}$ & $0.926^{* *}$ & $0.939 * *$ \\
\hline \multirow{2}{*}{ SHF-SF } & FAc & & & & & & & & & 0.738 & 0.183 & 0.084 & 0.649 & 0.231 & 0.693 & $0.836^{*}$ & 0.531 \\
\hline & pCAc & & & & & & & & & & -0.217 & -0.299 & 0.215 & 0.071 & 0.267 & 0.367 & 0.045 \\
\hline \multirow{7}{*}{ IF } & PCi & & & & & & & & & & & $0.955^{* *}$ & 0.789 & $0.897^{*}$ & 0.770 & 0.483 & 0.850 * \\
\hline & $\mathbf{A A i}$ & & & & & & & & & & & & 0.797 & 0.867 * & 0.718 & 0.407 & 0.813 * \\
\hline & FAi & & & & & & & & & & & & & 0.783 & $0.962^{* *}$ & 0.826 * & $0.940 * *$ \\
\hline & pCAi & & & & & & & & & & & & & & 0.793 & 0.481 & 0.820 * \\
\hline & 8O4DFA & & & & & & & & & & & & & & & 0.909 * & $0.974^{* *}$ \\
\hline & 55DFA & & & & & & & & & & & & & & & & 0.851 * \\
\hline & 85DFA & & & & & & & & & & & & & & & & \\
\hline
\end{tabular}


Contrary to the observations for maize flours, the hydrolysis of broa soluble phenolics (SF) (Figure 1) did not influence its soluble PC ( $p>0.05)$ (Table S4), which may indicate the presence of less interfering compounds. Nevertheless, the hydrolysis procedure also caused an average increase of $45 \pm 28 \%$ in broas soluble AA (Table S4) $(t=6.3, p<0.001)$, which was lower than the increase observed for maize flours (115 $\pm 45 \%)$. As previously discussed, this increase can be explained by higher free FA and pCA contents in the SHF. These findings imply that, in broas, the amount of FA and pCA released after hydrolysis was lower than in maize flours, due to lower contents in soluble-conjugated phenolics. Indeed, the contribution of compounds other than FA and pCA for the soluble AA of maize flours was around $99.0 \%$ (Table S3), while in broas it was around 96.9\% (Table S5) $(t=14.4$, $p<0.01)$.

Soluble-free FA and pCA and dicoumaroyl spermidine contents strongly influenced broas soluble AA $(R>0.86, p<0.05)$, while insoluble pCA and $8-5^{\prime}$-dehydrodiferulic acid strongly influenced broas insoluble AA $(R>0.81, p<0.05)$ (Table 4$)$. Since hydroxycinnamic acid amides and dehydrodiferulic acids were detected in broas as abundant phenolic compounds with antioxidant properties, they may contribute to broas health promoting effects. After consumption, dehydrodiferulic acids can be released from the matrix during digestion and further absorbed [38]. To the best of our knowledge, there is no data on hydroxycinnamic acid amides bioavailability, but it is known that other FA conjugates, such as feruloylated oligosaccharides, can be absorbed by a diffusion mechanism [4]. Additionally, some insoluble phenolics may also exhibit their beneficial action directly in the gastrointestinal system [4].

\subsection{Traditional and Commercial Maize Flours and Broas Comparison}

In order to study the main differences among maize samples varieties and corresponding broas, a principal component analysis (PCA) was performed using 16 variables, described in Tables 2 and 4. Figure 2 shows the projection of samples and variables in the space defined by the two principal components, corresponding to $82.2 \%$ of the total variance. Three sample clusters can be identified: (1) traditional maize flours, (2) traditional broas and (3) commercial maize flour and the corresponding broa, which are projected along different directions.

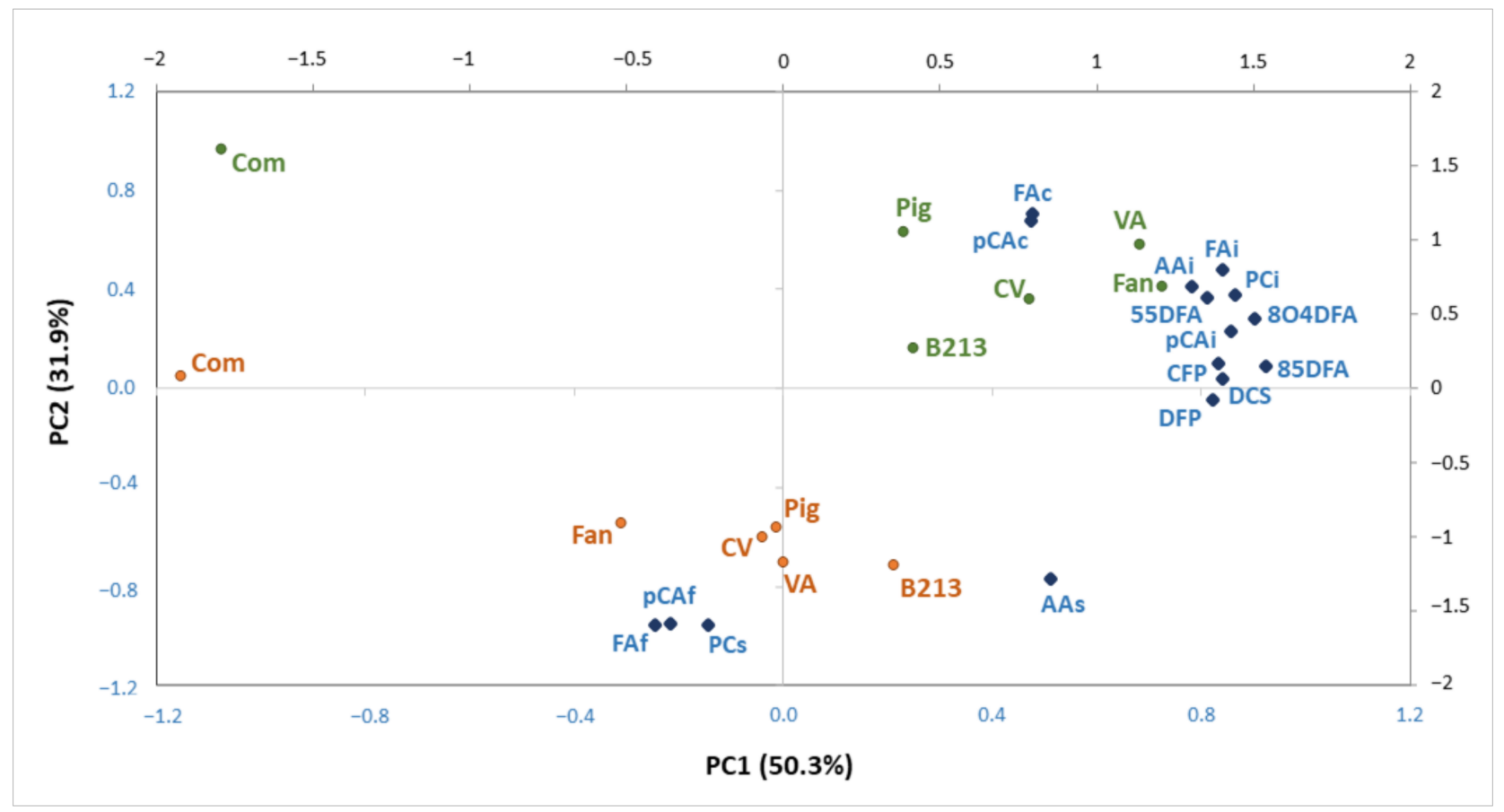

Figure 2. Projection of maize flours (green), broas (brown) and variables (blue) (Table 1) in the plane defined by PC1 and PC2, corresponding to $82.2 \%$ of total variance. 
The commercial maize flour and corresponding broa were differentiated from all the other samples along PC1, mainly due to the lower contents of insoluble phenolics and hydroxycinnamic acid amides, as described in Tables 1 and 3. Indeed, post hoc analysis revealed that the contents in hydroxycinnamic acid amides, 8-O-4'- and 8-5'-dehydrodiferulic acids of the commercial broa were significantly lower $(p<0.05)$ than all the traditional broas (Table 4). Similar results were observed for its soluble and total AA (Table 4). These differences can be explained by the different genotype and variety type, since it was a hybrid, whereas the traditional samples were open-pollinated varieties [25]; and also by its different edaphoclimatic and agronomic growing conditions [20,23]. Moreover, as previously reported, the commercial maize flour used in the present work presented a higher mean diameter and large particle distribution than the traditional flours [2]. This could have influenced not only the extraction of maize phenolic compounds, but also the amount of phenolic compounds released during the breadmaking process [13] and, consequently, the corresponding broa AA. As previously reported [2], a sensory evaluation study has demonstrated a preference for traditional in detriment of hybrid maize varieties for broa production, suggesting that, even without previous knowledge, consumers prefer broas with higher contents in these health promoting compounds.

Broas were discriminated from maize flours along PC2, mainly due to their higher contents of soluble PC and AA, as well as soluble-free FA and pCA, and by lower contents of soluble-conjugated FA and pCA. These results suggest that the content of soluble-free phenolics increased as a consequence of maize processing to broas, as discussed below.

\subsection{From Raw Flours to Broas}

All broas $(n=6)$ were prepared following the same recipe, which included not only maize flour, but also $20 \%$ rye and $10 \%$ wheat flours. Therefore, the values obtained for the raw flours' mixture (RF) that was used for the preparation of broas were calculated (Table S6) according to the expression:

$$
\mathrm{RF}=0.70 \times \mathrm{M}+0.20 \times R+0.10 \times \mathrm{W},
$$

where $\mathrm{M}, \mathrm{R}$ and $\mathrm{W}$ are the values presented in Table 2 for the different varieties of maize $(n=6)$ and for the rye and wheat flours, respectively. Results from raw flours and broas were compared based on the formula:

$$
100 \times \mathrm{B} / \mathrm{RF},
$$

which enabled the determination of the amount of AA, PC and individual phenolics remaining after raw flour (RF) processing to broas (B) (Table 6).

A paired-samples $t$-test was performed to compare the AA and phenolic composition of raw flours and the corresponding broas. The results presented in Table 6 show that the soluble PC and AA significantly increased in broas, possibly due to the increase ( $\geq$ threefold) in the soluble-free FA and pCA contents. Similar results have been obtained for other maize products, particularly for tortillas, tortilla chips and cornflakes $[1,18,20,31]$, as well as for other breads $[25,39]$. Some authors argued that the increase in soluble-free phenolics might be caused by the release of insoluble FA and pCA that occurs during breadmaking, especially during the fermentation process $[13,18,24,25,39,40]$. Therefore, a decrease in the insoluble phenolic content should be expected after processing. However, no significant differences $(p>0.05)$ were found concerning insoluble PC, AA, FA, pCA or dehydrodiferulic acids contents (Table 6). Different hypotheses can explain these results. Firstly, the amount of FA and pCA released during the processing corresponded only to $0.6-1.1 \%$ and $4.6-9.9 \%$ of the total FA and pCA contents originally present in the raw flours, corroborating the results described for rye processing to bread [39]. Secondly, a considerable amount of insoluble phenolics can remain linked to cell walls even after hydrolysis [4]. Ultimately, the increase in soluble-free phenolics might have been caused by the hydrolysis of soluble-conjugated phenolic compounds, in particular hydroxycinnamic 
acid amides [25]. Indeed, after processing, the soluble-conjugated FA and pCA contents decreased by around 27 and $44 \%$, respectively $(p<0.05)$ (Table 6$)$.

Table 6. Amount (\%) of phenolic content (PC), antioxidant activity (AA), ferulic acid (FA), p-coumaric acid (pCA), hydroxycinnamic acid amides (HCAAs) and dehydrodiferulic acids (DFAs) remaining after raw flour (70\% maize $+20 \%$ rye $+10 \%$ wheat) processing to broas.

\begin{tabular}{|c|c|c|c|c|c|c|c|c|c|}
\hline & & \multirow{2}{*}{ Fraction } & \multicolumn{6}{|c|}{ Samples } & \multirow{2}{*}{ Average } \\
\hline & & & B213 & Pig & $\mathrm{CV}$ & VA & Fan & Com & \\
\hline \multirow{3}{*}{ PC } & Soluble & SF & 153 & 181 & 176 & 176 & 201 & 198 & $181 \pm 17^{* *}$ \\
\hline & Insoluble & IF & 127 & 115 & 97 & 83 & 83 & 120 & $104 \pm 19$ \\
\hline & Total & $\mathrm{SF}+\mathrm{IF}$ & 133 & 126 & 110 & 99 & 100 & 137 & $118 \pm 17^{*}$ \\
\hline \multirow{3}{*}{ AA } & Soluble & SF & 139 & 147 & 138 & 149 & 140 & 128 & $140 \pm 7^{* *}$ \\
\hline & Insoluble & IF & 123 & 116 & 95 & 99 & 71 & 80 & $97 \pm 20$ \\
\hline & Total & $\mathrm{SF}+\mathrm{IF}$ & 127 & 120 & 103 & 107 & 79 & 88 & $104 \pm 18$ \\
\hline \multirow{5}{*}{ FA } & Soluble-free & SF & 298 & 350 & 333 & 305 & 353 & 380 & $337 \pm 31^{* *}$ \\
\hline & Soluble-conjugated & SHF-SF & 90 & 57 & 96 & 59 & 76 & 62 & $73 \pm 17 *$ \\
\hline & Total soluble & SHF & 109 & 75 & 119 & 75 & 100 & 80 & $93 \pm 19$ \\
\hline & Insoluble & IF & 130 & 94 & 91 & 81 & 70 & 123 & $98 \pm 24$ \\
\hline & Total & $\mathrm{SHF}+\mathrm{IF}$ & 128 & 93 & 92 & 80 & 69 & 119 & $97 \pm 23$ \\
\hline \multirow{5}{*}{$\mathrm{pCA}$} & Soluble-free & $\mathrm{SF}$ & 528 & 741 & 525 & 589 & 524 & 395 & $550 \pm 113^{\text {*** }}$ \\
\hline & Soluble-conjugated & SHF-SF & 80 & 45 & 72 & 56 & 47 & 95 & $66 \pm 20 *$ \\
\hline & Total Soluble & SHF & 130 & 93 & 127 & 106 & 59 & 143 & $110 \pm 31$ \\
\hline & Insoluble & IF & 115 & 110 & 97 & 79 & 60 & 83 & $91 \pm 21$ \\
\hline & Total & $\mathrm{SHF}+\mathrm{IF}$ & 115 & 108 & 99 & 82 & 59 & 95 & $93 \pm 20$ \\
\hline \multirow{3}{*}{ HCAAs } & DFP & SF & 96 & 131 & 89 & 107 & 98 & 117 & $106 \pm 15$ \\
\hline & CFP & SF & 84 & 116 & 85 & 90 & 69 & 111 & $92 \pm 18$ \\
\hline & DCS & SF & 100 & 137 & 98 & 91 & 87 & 86 & $100 \pm 19$ \\
\hline \multirow{3}{*}{ DFAs } & $8-\mathrm{O}-4^{\prime}$-DFA & IF & 177 & 98 & 100 & 74 & 60 & 110 & $103 \pm 41$ \\
\hline & 8-5'-DFA & IF & 192 & 71 & 102 & 81 & 58 & 97 & $100 \pm 48$ \\
\hline & $5-5^{\prime}-\mathrm{DFA}$ & IF & 173 & 103 & 130 & 102 & 92 & 104 & $117 \pm 30$ \\
\hline
\end{tabular}

* and **: Significant difference after raw flour processing to broas ( $p<0.05$ and $p<0.001$, respectively).

Since the soluble-conjugated FA and pCA contents decreased after processing, a decrease in the content of the main soluble-conjugated phenolics (hydroxycinnamic acid amides) would be expected. However, no differences were found between raw flours and broas regarding their content in diferuloyl putrescine, coumaroyl feruloyl putrescine or dicoumaroyl spermidine (Table 6). This suggests that insoluble hydroxycinnamic acid amides, recently described in maize flours and broas [11], may have been released during processing, therefore increasing the content of soluble hydroxycinnamic acid amides and soluble-free FA and pCA. Additionally, other minor soluble-conjugated compounds, namely, hydroxycinnamic acid amides monoconjugates, may have been hydrolyzed during processing, contributing to the higher soluble-free and lower soluble-conjugated FA and pCA contents detected in broas.

A comparison of traditional raw flours and broas' main phenolic compounds is presented in Figure 3. No significant differences $(p>0.05)$ were found between raw flours and broas regarding their total FA, pCA, hydroxycinnamic acid amides and dehydrodiferulic acids contents (Table 6). Contradictory results have been reported regarding the processing effects on the phenolic composition of other cereals, such as wheat and rye, to breads. Some authors concluded that the processing did not influence the content in the major phenolics, including FA and pCA [37]. On the other hand, some authors reported that the content of total phenolics and total FA, in particular, decreased after processing [39], while others have shown that it increased [25,41]. These discrepancies can be explained by differences in sample genotypes $[13,25,39]$ and breadmaking processing conditions, namely, in dough $\mathrm{pH}$, which influences the mechanical disaggregation of cell walls and the acidic hydrolysis 
that may occur during mixing $[13,25,39]$. No differences have been found between the dehydrodiferulic acids contents of rye flours and breads [25,39], which is in accordance to the present findings. To the best of our knowledge, hydroxycinnamic acid amides have not been considered in previous studies.

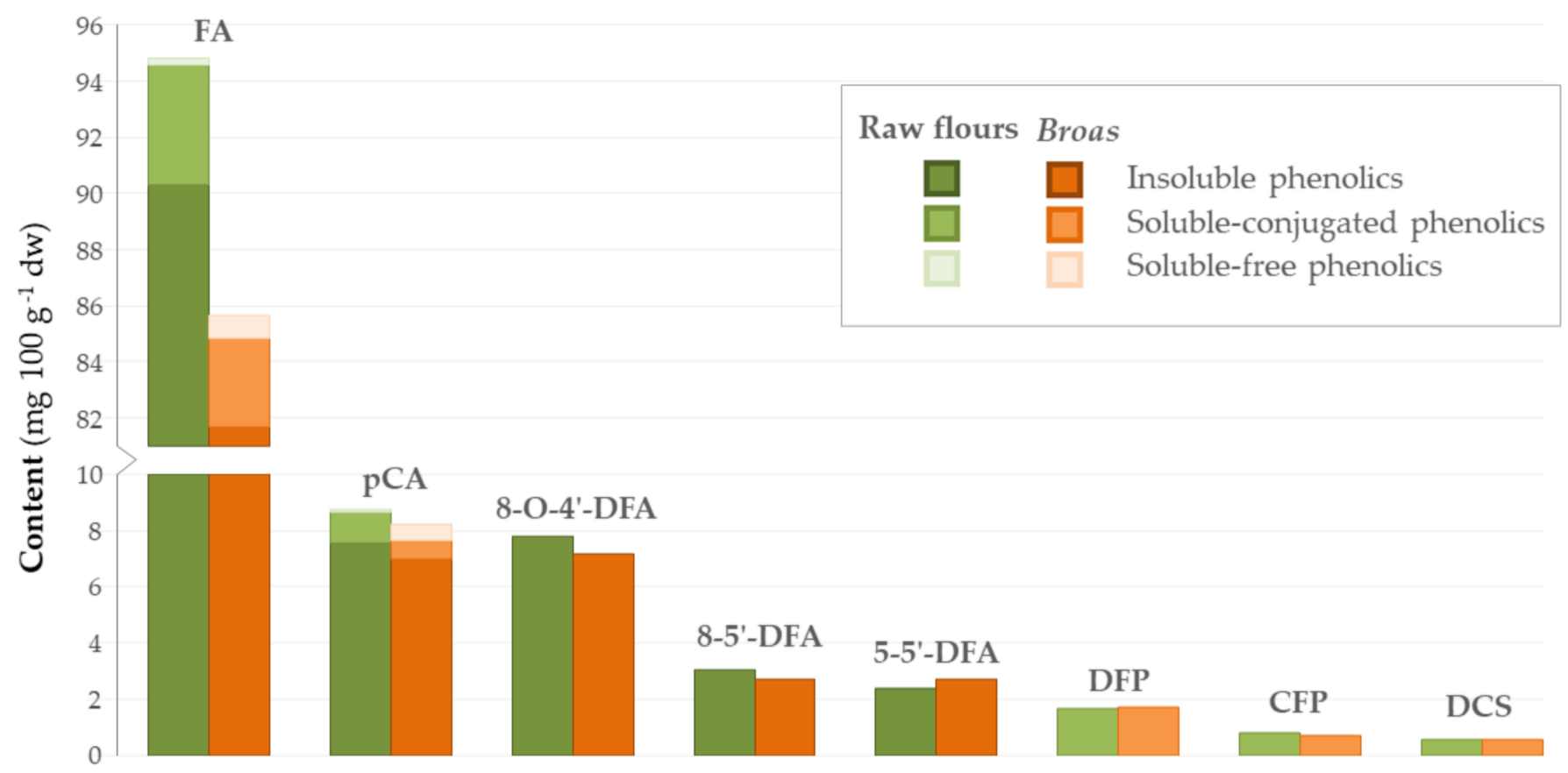

Figure 3. Average contents of phenolic compounds obtained for the traditional raw flours (green, $n=5$ ) and broas (brown, $n=5)$.

On the other hand, after maize grain processing into tortillas, there is a $56-90 \%$ reduction in the total PC, mainly due to leaching of insoluble FA during the nixtamalization process $[18,21,42]$. The content of phenolic acids also decreased after processing of maize into toasted cornflakes due to the pressure cooking stage and to the dry milling process, which involved the removal of maize bran and germ [31]. Therefore, the results obtained in the present work suggest that, in comparison to other maize-based foods, broas are an interesting source of phenolic compounds, since there were no significant losses in the total phenolics caused by the processing conditions, which were based on a traditional broa recipe.

\section{Conclusions}

Broa, a Portuguese traditional maize bread, can be considered an interesting source of antioxidant compounds, particularly hydroxycinnamic acids and hydroxycinnamic acid amides. Broas produced with Portuguese traditional open-pollinated maize varieties, which were, in a previous work, associated with better sensory characteristics, also showed higher phenolic content than the broa prepared with a commercial maize flour. The processing conditions used in broa preparation did not significantly change the phenolic content present in the raw flours used for its production. There was an increase in soluble-free phenolics after processing, suggesting that phenolic compounds' bioaccessibility was improved in broas. In vitro studies are currently being carried out to understand which compounds are bioavailable and may contribute to considering broa as a bread with healthpromoting properties.

Supplementary Materials: The following are available online at https:/ /www.mdpi.com/article/10 $.3390 /$ antiox10050672/s1. 
Author Contributions: Conceptualization, A.B.-S., M.R.B. and M.C.V.P.; methodology, A.B.-S., E.M., M.B. and A.T.S.; software, A.B.-S.; validation, A.B.-S., N.D., M.R.B. and M.C.V.P.; formal analysis, A.B.-S. and A.T.S.; investigation, A.B.-S., E.M. and M.B.; resources, M.R.B. and M.C.V.P.; data curation, A.B.-S.; writing-original draft preparation, A.B.-S.; writing-review and editing, A.B.-S., N.D., M.R.B. and M.C.V.P.; visualization, A.B.-S.; supervision, M.R.B.; project administration, M.R.B. and M.C.V.P.; funding acquisition, M.R.B. and M.C.V.P. All authors have read and agreed to the published version of the manuscript.

Funding: This research was funded by the European Union's Seventh Framework Programme for research, technological development and demonstration under grant agreement number 245058, by the Fundação Para a Ciência e Tecnologia and Portugal 2020 to the Portuguese Mass Spectrometry Network, grant number LISBOA-01-0145-FEDER-402-022125 and by Fundação Para a Ciência e Tecnologia through research unit Green-IT (UID/Multi/04551/2020).

Institutional Review Board Statement: Not applicable.

Informed Consent Statement: Not applicable.

Data Availability Statement: The data supporting the findings of this study are available within the article and its supplementary material.

Acknowledgments: The authors are grateful to Carla Brites and Bruna Carbas from INIAV for their assistance with broas preparation and determination of flours moisture.

Conflicts of Interest: The authors declare no conflict of interest. The funders had no role in the design of the study; in the collection, analyses, or interpretation of data; in the writing of the manuscript, or in the decision to publish the results.

\section{References}

1. Singh, N.; Singh, S.; Shevkani, K. Maize: Composition, bioactive constituents, and unleavened bread. In Flour and Breads and Their Fortification in Health and Disease Prevention; Elsevier: Amsterdam, The Netherlands, 2019; pp. 111-121.

2. Carbas, B.; Patto, M.C.V.; Bronze, M.R.; Bento-Da-Silva, A.; Trigo, M.J.; Brites, C. Maize Flour Parameters That Are Related to the Consumer Perceived Quality of 'Broa' Specialty Bread. Food Sci. Technol. 2016, 36, 259-267. [CrossRef]

3. Angelino, D.; Cossu, M.; Marti, A.; Zanoletti, M.; Chiavaroli, L.; Brighenti, F.; Del Rio, D.; Martini, D. Bioaccessibility and Bioavailability of Phenolic Compounds in Bread: A Review. Food Funct. 2017, 8, 2368-2393. [CrossRef] [PubMed]

4. Bento-Silva, A.; Patto, M.C.V.; Bronze, M.R. Relevance, Structure and Analysis of Ferulic Acid in Maize Cell Walls. Food Chem. 2017, 246, 360-378. [CrossRef]

5. Salinas-Moreno, Y.; García-Salinas, C.; Ramírez-Díaz, J.L.; Alemán-de la Torre, I. Phenolic Compounds in Maize Grains and Its Nixtamalized Products. In Phenolic Compounds-Natural Sources, Importance and Applications; Intech: London, UK, 2017.

6. Buitimea-Cantúa, N.E.; Gutiérrez-Uribe, J.A.; Serna-Saldivar, S.O. Phenolic-Protein Interactions: Effects on Food Properties and Health Benefits. J. Med. Food 2018, 21, 188-198. [CrossRef] [PubMed]

7. Choi, S.W.; Lee, S.K.; Kim, E.O.; Oh, J.H.; Yoon, K.S.; Parris, N.; Hicks, K.B.; Moreau, R.A. Antioxidant and Antimelanogenic Activities of Polyamine Conjugates from Corn Bran and Related Hydroxycinnamic Acids. J. Agric. Food Chem. 2007, 55, $3920-3925$. [CrossRef]

8. Collison, A.; Yang, L.; Dykes, L.; Murray, S.; Awika, J.M. Influence of Genetic Background on Anthocyanin and Copigment Composition and Behavior during Thermoalkaline Processing of Maize. J. Agric. Food Chem. 2015, 63, 5528-5538. [CrossRef]

9. Xiang, J.; Zhang, M.; Apea-Bah, F.B.; Beta, T. Hydroxycinnamic Acid Amide (HCAA) Derivatives, Flavonoid C-Glycosides, Phenolic Acids and Antioxidant Properties of Foxtail Millet. Food Chem. 2019, 295, 214-223. [CrossRef]

10. Gutiérrez-Grijalva, E.P.; Ambriz-Pére, D.L.; Leyva-López, N.; Castillo-López, R.I.; Heredia, J.B. Dietary Phenolic Compounds, Health Benefits and Bioaccessibility. Arch. Latinoam. Nutr. 2016, 66, 87-100.

11. Bento-Silva, A.; Duarte, N.; Mecha, E.; Belo, M.; Patto, M.C.V.; Bronze, M.R. Hydroxycinnamic Acids and Their Derivatives in Broa, a Traditional Ethnic Maize Bread. Foods 2020, 9, 1471. [CrossRef]

12. Ribas-Agustí, A.; Martín-Belloso, O.; Soliva-Fortuny, R.; Elez-Martínez, P. Food Processing Strategies to Enhance Phenolic Compounds Bioaccessibility and Bioavailability in Plant-Based Foods. Crit. Rev. Food Sci. Nutr. 2018, 58, 2531-2548. [CrossRef]

13. Wang, T.; He, F.; Chen, G. Improving Bioaccessibility and Bioavailability of Phenolic Compounds in Cereal Grains through Processing Technologies: A Concise Review. J. Funct. Foods 2014, 7, 101-111. [CrossRef]

14. Brites, C.M.; Trigo, M.J.; Carrapiço, B.; Alviña, M.; Bessa, R.J. Maize and Resistant Starch Enriched Breads Reduce Postprandial Glycemic Responses in Rats. Nutr. Res. 2011, 31, 302-308. [CrossRef] [PubMed]

15. Mussi de Mira, N.V.; Cerdeira Barros, R.M.; Schiocchet, M.A.; Noldin, J.A.; Lanfer-Marquez, U.M. Extração, Análise e Distribuição Dos Ácidos Fenólicos Em Genótipos Pigmentados e Não Pigmentados de Arroz (Oryza sativa L.). Cienc. Technol. 2008, 28, 994-1002. 
16. Dobberstein, D.; Bunzel, M. Separation and Detection of Cell Wall-Bound Ferulic Acid Dehydrodimers and Dehydrotrimers in Cereals and Other Plant Materials by Reversed Phase High-Performance Liquid Chromatography with Ultraviolet Detection. J. Agric. Food Chem. 2010, 58, 8927-8935. [CrossRef]

17. Serra, A.T.; Matias, A.A.; Frade, R.F.M.; Duarte, R.O.; Feliciano, R.P.; Bronze, M.R.; Figueira, M.E.; de Carvalho, A.; Duarte, C.M.M. Characterization of Traditional and Exotic Apple Varieties from Portugal. Part 2-Antioxidant and Antiproliferative Activities. J. Funct. Foods 2010, 2, 46-53. [CrossRef]

18. De la Parra, C.; Serna Saldivar, S.O.; Liu, R.H. Effect of Processing on the Phytochemical Profiles and Antioxidant Activity of Corn for Production of Masa, Tortillas, and Tortilla Chips. J. Agric. Food Chem. 2007, 55, 4177-4183. [CrossRef]

19. Lopez-Martinez, L.X.; Oliart-Ros, R.M.; Valerio-Alfaro, G.; Lee, C.-H.; Parkin, K.L.; Garcia, H.S. Antioxidant Activity, Phenolic Compounds and Anthocyanins Content of Eighteen Strains of Mexican Maize. LWT_Food Sci. Technol. 2009, 42, 1187-1192. [CrossRef]

20. Mora-Rochin, S.; Gutiérrez-Uribe, J.A.; Serna-Saldivar, S.O.; Sánchez-Peña, P.; Reyes-Moreno, C.; Milán-Carrillo, J. Phenolic Content and Antioxidant Activity of Tortillas Produced from Pigmented Maize Processed by Conventional Nixtamalization or Extrusion Cooking. J. Cereal Sci. 2010, 52, 502-508. [CrossRef]

21. Aguayo-Rojas, J.; Mora-Rochín, S.; Cuevas-Rodríguez, E.O.; Serna-Saldivar, S.O.; Gutierrez-Uribe, J.A.; Reyes-Moreno, C.; Milán-Carrillo, J. Phytochemicals and Antioxidant Capacity of Tortillas Obtained after Lime-Cooking Extrusion Process of Whole Pigmented Mexican Maize. Plant Foods Hum. Nutr. 2012, 67, 178-185. [CrossRef]

22. Gutiérrez-Uribe, J.A.; Rojas-García, C.; García-Lara, S.; Serna-Saldivar, S.O. Phytochemical Analysis of Wastewater (Nejayote) Obtained after Lime-Cooking of Different Types of Maize Kernels Processed into Masa for Tortillas. J. Cereal Sci. 2010, 52, 410-416. [CrossRef]

23. Urias-Lugo, D.A.; Heredia, J.B.; Serna-Saldivar, S.O.; Muy-Rangel, M.D.; Valdez-Torres, J.B. Total Phenolics, Total Anthocyanins and Antioxidant Capacity of Native and Elite Blue Maize Hybrids (Zea mays L.). CyTA-J. Food 2015, 13, 336-339. [CrossRef]

24. Antognoni, F.; Mandrioli, R.; Bordoni, A.; Di Nunzio, M.; Viadel, B.; Gallego, E.; Villalba, M.P.; Tomás-Cobos, L.; Taneyo Saa, D.L.; Gianotti, A. Integrated Evaluation of the Potential Health Benefits of Einkorn-Based Breads. Nutrients 2017, 9, 1232. [CrossRef]

25. Dynkowska, W.M.; Cyran, M.R.; Ceglińska, A. Soluble and Cell Wall-bound Phenolic Acids and Ferulic Acid Dehydrodimers in Rye Flour and Five Bread Model Systems: Insight into Mechanisms of Improved Availability. J. Sci. Food Agric. 2015, 95, 1103-1115. [CrossRef]

26. Bastola, K.P.; Guragain, Y.N.; Bhadriraju, V.; Vadlani, P.V. Evaluation of Standards and Interfering Compounds in the Determination of Phenolics by Folin-Ciocalteu Assay Method for Effective Bioprocessing of Biomass. Am. J. Anal. Chem. 2017, 8, 416. [CrossRef]

27. Teixeira, J.; Gaspar, A.; Garrido, E.M.; Garrido, J.; Borges, F. Hydroxycinnamic Acid Antioxidants: An Electrochemical Overview. Biomed. Res. Int. 2013, 2013. [CrossRef] [PubMed]

28. Oliveira-Neto, J.R.; Rezende, S.G.; de Fátima Reis, C.; Benjamin, S.R.; Rocha, M.L.; de Souza Gil, E. Electrochemical Behavior and Determination of Major Phenolic Antioxidants in Selected Coffee Samples. Food Chem. 2016, 190, 506-512. [CrossRef] [PubMed]

29. Das, A.K.; Singh, V. Antioxidative Free and Bound Phenolic Constituents in Pericarp, Germ and Endosperm of Indian Dent (Zea mays Var. Indentata) and Flint (Zea mays Var. Indurata) Maize. J. Funct. Foods 2015, 13, 363-374.

30. Ndolo, V.U.; Beta, T. Comparative Studies on Composition and Distribution of Phenolic Acids in Cereal Grain Botanical Fractions. Cereal Chem. 2014, 91, 522-530. [CrossRef]

31. Butts-Wilmsmeyer, C.J.; Mumm, R.H.; Rausch, K.D.; Kandhola, G.; Yana, N.A.; Happ, M.M.; Ostezan, A.; Wasmund, M.; Bohn, M.O. Changes in Phenolic Acid Content in Maize during Food Product Processing. J. Agric. Food Chem. 2018, 66, 3378-3385. [CrossRef]

32. Moreau, R.A.; Nuñez, A.; Singh, V. Diferuloylputrescine and P-Coumaroyl-Feruloylputrescine, Abundant Polyamine Conjugates in Lipid Extracts of Maize Kernels. Lipids 2001, 36, 839-844. [CrossRef]

33. Jia, Y.; He, Y.; Lu, F. The Structure-Antioxidant Activity Relationship of Dehydrodiferulates. Food Chem. 2018, 269 , 480-485. [CrossRef]

34. Gupta, K.; Dey, A.; Gupta, B. Plant Polyamines in Abiotic Stress Responses. Acta Physiol. Plant. 2013, 35, 2015-2036. [CrossRef]

35. Butts-Wilmsmeyer, C.J.; Mumm, R.H.; Bohn, M.O. Quantitative Genetic Analysis of Hydroxycinnamic Acids in Maize (Zea mays L.) for Plant Improvement and Production of Health-Promoting Compounds. J. Agric. Food Chem. 2020, 68, 9585-9593. [CrossRef] [PubMed]

36. Pal, M.; Janda, T. Role of Polyamine Metabolism in Plant Pathogen Interactions. J. Plant Sci. Phytopathol. 2017, 1, 95-100.

37. Mattila, P.; Pihlava, J.; Hellström, J. Contents of Phenolic Acids, Alkyl- and Alkenylresorcinols, and Avenanthramides in Commercial Grain Products. J. Agric. Food Chem. 2005, 53, 8290-8295. [CrossRef]

38. Andreasen, M.F.; Kroon, P.A.; Williamson, G.; Garcia-Conesa, M.-T. Intestinal Release and Uptake of Phenolic Antioxidant Diferulic Acids. Free Radic. Biol. Med. 2001, 31, 304-314. [CrossRef]

39. Hansen, H.B.; Andreasen, M.; Nielsen, M.; Larsen, L.; Knudsen, B.K.; Meyer, A.; Christensen, L. Changes in Dietary Fibre, Phenolic Acids and Activity of Endogenous Enzymes during Rye Bread-Making. Eur. Food Res. Technol. 2002, $214,33-42$. [CrossRef]

40. Ragaee, S.; Seetharaman, K.; Abdel-Aal, E.-S.M. The Impact of Milling and Thermal Processing on Phenolic Compounds in Cereal Grains. Crit. Rev. Food Sci. Nutr. 2014, 54, 837-849. [CrossRef] [PubMed] 
41. Gelinas, P.; McKinnon, C.M. Effect of Wheat Variety, Farming Site, and Bread-baking on Total Phenolics. Int. J. Food Sci. Technol. 2006, 41, 329-332. [CrossRef]

42. Del Pozo-Insfran, D.; Brenes, C.H.; Saldivar, S.O.S.; Talcott, S.T. Polyphenolic and Antioxidant Content of White and Blue Corn (Zea mays L.) Products. Food Res. Int. 2006, 39, 696-703. [CrossRef] 